\title{
Plant growth enhancement and associated physiological responses are coregulated by ethylene and gibberellin in response to harpin protein Hpa1
}

\author{
Xiaojie Li • Bing Han • Manyu Xu • Liping Han • \\ Yanying Zhao $\cdot$ Zhilan Liu $\cdot$ Hansong Dong $\cdot$ \\ Chunling Zhang
}

Received: 1 September 2013 / Accepted: 12 December 2013 / Published online: 7 January 2014

(C) The Author(s) 2014. This article is published with open access at Springerlink.com

\begin{abstract}
The harpin protein Hpal produced by the bacterial blight pathogen of rice induces several growth-promoting responses in plants, activating the ethylene signaling pathway, increasing photosynthesis rates and EXPANSIN $(E X P)$ gene expression levels, and thereby enhancing the vegetative growth. This study was attempted to analyze any mechanistic connections among the above and the role of gibberellin in these responses. Hpa1-induced growth enhancement was evaluated in Arabidopsis, tomato, and rice. And growth-promoting responses were determined mainly as an increase of chlorophyll a/b ratio, which indicates a potential elevation of photosynthesis rates, and enhancements of photosynthesis and EXP expression in the three plant species. In Arabidopsis, Hpa1-induced growthpromoting responses were partially compromised by a defect in ethylene perception or gibberellin biosynthesis. In tomato and rice, compromises of Hpa1-induced growthpromoting responses were caused by a pharmacological
\end{abstract}

X. Li and B. Han contributed equally to this study.

Electronic supplementary material The online version of this article (doi:10.1007/s00425-013-2013-y) contains supplementary material, which is available to authorized users.

X. Li · B. Han · M. Xu · L. Han · Y. Zhao · Z. Liu · H. Dong $(\square) \cdot$

C. Zhang $(\bowtie)$

State Ministry of Education Key Laboratory of Integrated

Management of Crop Pathogens and Insect Pests, Nanjing

Agricultural University, Nanjing 210095, China

e-mail: hsdong@njau.edu.cn

C. Zhang

e-mail: zhangcl@njau.edu.cn

X. Li

Tobacco Research Institute, Henan Provincial Academy

of Agricultural Sciences, Xuchang 461000, China treatment with an ethylene perception inhibitor or a gibberellin biosynthesis inhibitor. In the three plant species, moreover, Hpa1-induced growth-promoting responses were significantly impaired, but not totally eliminated, by abolishing ethylene perception or gibberellin synthesis. However, simultaneous nullifications in both ethylene perception and gibberellin biosynthesis almost canceled the full effects of Hpal on plant growth, photosynthesis, and EXP2 expression. Theses results suggest that ethylene and gibberellin coregulate Hpa1-induced plant growth enhancement and associated physiological and molecular responses.

Keywords Ethylene $\cdot$ Gibberellin $\cdot$ Hpa1 $\cdot$ Plant growth enhancement $\cdot$ Signal transduction

Abbreviations
$\begin{array}{ll}A_{\mathrm{N}} & \text { Net photosynthesis }\left(\mathrm{CO}_{2} \text { assimilation }\right) \\ \text { ert1-1 } & \begin{array}{l}\text { An Arabidopsis mutant with a defect in the } \\ \text { ethylene receptor ETR1 }\end{array} \\ \text { EXP } & \begin{array}{l}\text { Expansin } \\ \text { EVP }\end{array} \\ \text { Ea5-1 } & \begin{array}{l}\text { An Arabidy vector preparation } \\ \text { gibberellin biosynthesis }\end{array} \\ \text { etrl ga5-1 } & \text { The double mutant } \\ \text { LSD } & \text { Fisher's least significant difference } \\ 1-M C P & \text { 1-Methylcyclopropene } \\ \text { PBZ } & \text { Paclobutrazol in the } \\ \text { RT-PCR } & \text { Reverse transcriptase-polymerase chain } \\ & \text { reaction }\end{array}$

Introduction

Harpin proteins produced by Gram-negative plant pathogenic bacteria have multifaceted functions in a variety of 
plant species and have drawn great attention in the last two decades (Wei et al. 1992; He et al. 1993; Kim and Beer 2000; Desikan et al. 2001; Alfano and Collmer 2004; Liu et al. 2006; Oh and Beer 2007; Chen et al. 2008a, b; Miao et al. 2010; Sang et al. 2012; Choi et al. 2013; Li et al. 2014). After ectopic expression in transgenic plants or external application to plants, harpins activate distinct signaling pathways to induce different beneficial effects (Chen et al. 2008a). In response to a harpin protein, the salicylic acid signaling pathway is activated to confer induced resistance against pathogens (Strobel et al. 1996; Dong et al. 1999; Peng et al. 2004; Sang et al. 2012), while abscisic acid signaling is triggered to regulate the induction of drought tolerance (Dong et al. 2005; Zhang et al. 2011a). In response to a harpin protein, moreover, the ethylene signaling pathway diverges downstream of the ethylene perception step into two distinct circuits: one leads to induced resistance against insect pests (Dong et al. 2004; Liu et al. 2011; Lü et al. 2013a; Zhang et al. 2011b), and the other results in plant growth enhancement (Dong et al. 2004; Ren et al. 2006a, b, 2008; Zhang et al. 2007; Chen et al. 2008a, b; Li et al. 2014). Overall, harpins have been recognized as multifunctional elicitors in plants.

One such harpin is Hpa1 secreted by Xanthomonas oryzae, an important bacterial pathogen of rice (Zhu et al. 2000; Peng et al. 2004; Liu et al. 2006). Hpa1 causes multiple beneficial effects in different plants (Peng et al. 2004; Liu et al. 2006; Ren et al. 2006a, b; Miao et al. 2010; Zhang et al. 2011a, b) and possesses all functions characterized early for its orthologs identified in different bacterial species (Wei et al. 1992; He et al. 1993; Strobel et al. 1996; Dong et al. 1999). This study pays a main attention to Hpa1-induced plant growth enhancement and associated growth-promoting responses at physiological and molecular levels. In different plants, Hpa1-induced growth-promoting responses have been shown as activated ethylene signaling pathway, promoted photosynthesis, and enhanced expression of EXPANSIN (EXP) genes, and these responses result in plant growth enhancement (Ren et al. 2006a, b; Wu et al. 2007; Chen et al. 2008a, b; Li et al. 2014). This study focuses on current questions in regard to any mechanistic connections among Hpa1-induced growth-promoting responses.

The first question concerns the functional relationship between the concomitant roles of Hpal in activating the ethylene signaling pathway and inducing the expression of EXP genes (Ren et al. 2006a, b; Wu et al. 2007; Chen et al. 2008a; Li et al. 2014). EXP genes encode expansin (EXP) proteins that have unique "loosening" effects on plant cell walls and form a super protein family in plants (Sampedro and Cosgrove 2005). Members in the family function in different aspects of plant growth and development, such as cell elongation and separation, cell wall disassembly, formation of leaf primordia, and morphogenesis of root hairs (Cosgrove 2001; Cho and Cosgrove 2002; Colmer et al. 2004; Sampedro and Cosgrove 2005; Zhao et al. 2012; Lü et al. 2013b). Among hundreds of EXPs identified in different plant species (http://www.bio.psu.edu/expansins/ other_species.htm), EXP1 and EXP2 orthologs have been demonstrated to be required for the vegetative growth (Cox et al. 2004; Sloan et al. 2009; Wang et al. 2011). Especially, enhanced expression of EXP1 and EXP2 genes contributes to plant growth enhancement by Hpa1 either expressed in transgenic plants or applied to plants (Ren et al. 2006a, b; Wu et al. 2007; Chen et al. 2008a). In Hpa1-expressing transgenic rice (Oryza sativa) lines or rice plants treated with Hpa1, growth enhancement is correlated with enhanced expression of OsEXP1 (Ren et al. 2006a, b; Chen et al. 2008a). In Arabidopsis thaliana plants treated with Hpa1, AtEXP1 and AtEXP2 are highly expressed compared to the steady-state level of the expression in control plants (Li et al. 2014). Similarly, tea (Camellia sinensis) orthologs of EXP1, EXP10, and EXP18 are highly upregulated at the transcription level following the Hpal treatment (Wu et al. 2007). In these study cases, enhanced EXP expression correlates not only with enhanced vegetative growth, but also with increased output of the crop product (rice grain or tea leaves used as drinking material) (Ren et al. 2006a, b; Wu et al. 2007; Chen et al. 2008a, b). However, these studies only demonstrate the concomitance in ethylene signaling and EXP gene expression, but do not offer evidence for causal relationship between both responses. Indeed, there is as yet no study to establish any mechanistic or physiological connections between ethylene signaling and EXP expression although they coordinately respond to Hpal.

The second question is regarding the roles of phytohormones, in addition to ethylene, in Hpa1-induced growthpromoting responses, especially EXP expression. Published studies demonstrate that auxin, ethylene, and gibberellin induce or inhibit EXP expression depending on the types of EXP orthologs and plant tissues or growth conditions. For instance, exogenous gibberellin induces the expression of OsEXP4 to promote internode growth of deepwater rice (Cho and Kende 1997), but exogenous auxin represses OsEXP1 expression in the plant under infection by $X$. oryzae (Ding et al. 2008). In Arabidopsis, auxin and ethylene induce AtEXP7 and AtEXP8 expression to regulate root hair initiation (Cho and Cosgrove 2002). Both hormones also induce the expression of LeEXP1 and LeEXP 2 in ripening fruits of tomato (Lycopersicon esculentum) (Rose and Bennett 1999). In tomato plants, moreover, imbalance of auxin and ethylene is responsible for the inhibitory effect of the toxic compound cyanamide on root growth associated with LeEXP9 and LeEXP18 expression (Soltys et al. 2012). However, LeEXP9 expression in the young stem requires gibberellin and contributes to cell elongation in the organ 
(Vogler et al. 2003). Apparently, EXP expression induced by ethylene or auxin is related to defense responses (Ding et al. 2008; Soltys et al. 2012; Zhao et al. 2012) and regulation of development or morphogenesis (Rose and Bennett 1999; Cho and Cosgrove 2002); whereas, gibberellininduced EXP expression associates with the vegetative growth (Cho and Kende 1997; Vogler et al. 2003). Therefore, it is great of interest to study the possible role of gibberellin in Hpa1-induced plant growth enhancement and growth-promoting responses.

An additional question is related to photosynthesis as a fundamental basis of plant growth and Hpa1-induced plant growth enhancement (Li et al. 2014). In Arabidopsis, externally applied Hpa1 facilitates gas exchanges in mesophyll cells or mesophyll conductance to $\mathrm{CO}_{2}$, promotes $\mathrm{CO}_{2}$ transport from substomatal cavities into mesophyll cells, and therefore increases net photosynthesis $/ \mathrm{CO}_{2}$ assimilation $\left(A_{\mathrm{N}}\right)$ rates. This physiological response critically contributes to growth enhancement of the plant by Hpal $(\mathrm{Li}$ et al. 2014). Whether any hormone plays a role of Hpa1promoted photosynthesis is unknown until now.

This study was attempted to elucidate a mechanistic connection between the functions of Hpa1 in activating the ethylene signaling pathway and in eliciting plant growthpromoting responses shown as changes in $A_{\mathrm{N}}$ rates and EXP expression. The role of gibberellin in the responses was also analyzed.

\section{Materials and methods}

\section{Protein preparations}

Proteins used in this study were prepared as previously described (Chen et al. 2008a). Proteins were produced by Escherichia coli cells transformed with the prokaryotic expression vector $\mathrm{pET} 30 \mathrm{a}(+)$ (empty vector) or the recombinant vector containing an insert of the $X$. oryzae hpal gene, which had been fused to the histidine (His) tag coding sequence. The empty vector preparation (EVP) and the Hpa1-His fusion protein preparation were purified by nickel chromatography and elution with imidazole. Highly purified Hpa1-His protein was collected from the 200-mM imidazole eluent and used in the experiments after the His tag was removed by treatment with the Novagen Enterokinase Cleavage Capture Kit (EMD Biosciences Inc., Darmstadt, Germany). The 200-mM imidazole eluent of the EVP preparation was used as a negative control in the experiments.

Plant material, treatment, and growth scoring

Arabidopsis genotypes used in this study were the ecotype Col-0, its mutants etrl-1 and ga5-1 generated previously (seed stock numbers CS1092, CS237, and CS62; http:// arabidopsis.org), and the etrl-1 ga5-1 double mutant generated by pollinating etr $1-1$ with pollens of ga5-1. Seeds of the tomato (Lycopersicon esculentum) variety Xiafen were purchased from a local market. Seeds of the rice (Oryza sativa) variety IRBB10 were maintained in this lab. Seeds were disinfested in a $1.5 \%(\mathrm{w} / \mathrm{v})$ solution of sodium hypochlorite for $10 \mathrm{~min}$ before sowing or treatment.

Highly purified Hpal was prepared as a $15 \mu \mathrm{g} \mathrm{mL}-1$ aqueous solution amended with the surfactant Silwet-37 at $0.03 \%(\mathrm{v} / \mathrm{v})$. The mixture was used to immerse disinfected seeds. Treated Arabidopsis seeds were incubated on Murashige and Skoog agar medium in $10-\mathrm{cm}$ square plates, and the treated tomato and rice seeds were incubated on wet filter papers in 9-cm Petri dishes. Alternatively, disinfected seeds were sown directly in $60-\mathrm{ml}$ pots filled with potting soil (Dong et al. 2005) and 10-day-old seedlings were treated with the Hpal solution by spraying over plant tops. In the experimental control group, highly pure water and an aqueous solution of EVP were amended with $0.03 \%$ Silwet-37 and applied separately to seeds or plants similarly as the application of Hpa1. Plants in pots and on plates were grown in environmentally controlled chambers with a 12-h day (200 $\mu \mathrm{mol}$ photons $\mathrm{m}^{-2} \mathrm{~s}^{-1}$ and $24^{\circ} \mathrm{C}$ ) and 12-h night $\left(20^{\circ} \mathrm{C}\right)$ cycle. Root length of plants grown on the medium and fresh weight of plants grown in pots were surveyed.

Physiological studies

Leaf content of total nitrogen was determined by a previously described method (Lang 1958). Concentrations of chlorophyll $\mathrm{a}$ and $\mathrm{b}$ were analyzed with Single-Photon Avalanche Diode (SPAD) meter (SPAD-502, Minota, Tokyo, Japan) and quantified as $\mathrm{mg} \mathrm{cm}^{-2}$ leaf (Kourill et al. 1999; Yang et al. 2003). Leaf photosynthesis was analyzed with the Li-6400XT portable photosynthesis system and equipped leaf chambers (LI-COR, Inc., Lincoln, NE, USA). Detailed measurements were accomplished by following the manufacturer's instructions and experimental procedures described previously (Flexas et al. 2007; Heckwolf et al. 2011). Gas concentrations at the inlet and outlet of leaf chambers were monitored by the non-dispersive infrared gas analyzer installed in the system. Instantaneous gas exchange measurements were performed several times during the experiments at saturating light (photosynthetically active photon flux density of $1,500 \mu \mathrm{mol} \mathrm{m} \mathrm{m}^{-2} \mathrm{~s}^{-1}$ ) and the chamber $\mathrm{CO}_{2}$ concentration of $400 \mu \mathrm{M} \mathrm{M}^{-1}$ air. Values of $A_{\mathrm{N}}$ were recorded by the S-501 digital monitor integrated into the system.

Endogenous ethylene and gibberellin concentrations were analyzed. The production of ethylene in plants was determined by a previously described protocol (Dong et al. 
2004). Gibberellin content was analyzed as previously described (Foster et al. 1994). Gibberellin isoforms were extracted from growing stems of tomato and rice or the aerial parts of Arabidopsis, purified using a combination of preparatory column chromatography, and analyzed with reverse-phase high-performance liquid chromatography. Deuterated internal standards were added, $20 \mathrm{ng}$ of [17,17$\left.{ }^{2} \mathrm{H}_{2}\right] \mathrm{GA} 12$ and $25 \mathrm{ng}\left[17,17-{ }^{2} \mathrm{H}_{2}\right] \mathrm{GA} 1$, -GA8, -GA19, -GA20, -GA44, and -GA53, respectively. Tritiated standards $\left(1,500 \mathrm{~Bq}\left[1,2-{ }^{3} \mathrm{H}_{2}\right] \mathrm{GA} 1\right.$ and $\left[1,2-{ }^{3} \mathrm{H}_{2}\right] \mathrm{GA} 4$, respectively) were also added to the combined extract to monitor recovery through the purification procedure. Gas was quantified using GC-MS selected ion monitoring by calculating the area ratio of endogenous gibberellin to the deuterated standard gibberellin that had been added during the extraction step, and the contribution from the deuterated standard to the nondeuterated gibberellin was corrected (Beall et al. 1991). The concentration of total gibberellin (a sum of different isoforms) was quantified in contrast to fresh weight of plant tissues used in gibberellin isolation.

\section{Gene expression analysis}

Gene expression was analyzed by reverse transcriptasepolymerase chain reaction (RT-PCR) and real-time RTPCR (Chen et al. 2008a; Liu et al. 2011). The constitutively expressed EFl $\alpha$ and Actin genes were used as references. Genes tested and specific primers are provided in Supplementary Table S1. In real-time RT-PCR analysis, no template control was included to verify amounts of gene transcripts. The amount of a gene transcript was quantified relative to $E F 1 \alpha$.

\section{Pharmacological study}

Chemicals used in pharmacological study were the gibberellin biosynthesis inhibitor paclobutrazol (PBZ; Shanghai Chemical Reagent Co., Shanghai, China) and the ethylene signaling inhibitor 1-methylcyclopropene (1-MCP; Lytone Enterprise Inc., Nanjing Agency). PBZ was used at a physiologically active concentration $(1 \mu \mathrm{M}$; Li et al. 2014) together with the Hpal solution to treat seeds or plants. 1-MCP was applied at a physiologically active concentration $\left(0.225 \mu 1 \mathrm{~L}^{-1}\right)$ to plants as previously described (Zhang et al. 2007; Ren et al. 2008). 1-MCP was supplied as $1.1 \mathrm{~g}$ water-volatilizable tablets containing $0.18 \%$ active ingredient, and each tablet was determined by the supplier to release $0.9 \mu \mathrm{L} \mathrm{L}^{-1}$ gaseous $1-\mathrm{MCP}$ in a $1-\mathrm{cm}^{3}$ space (equivalent to $0.075 \mu \mathrm{L} \mathrm{L}^{-1}$ gaseous $1-\mathrm{MCP}$ in a $12-\mathrm{cm}^{3}$ space) at $20{ }^{\circ} \mathrm{C}$ and $70 \%$ humidity. The plant treatment with 1-MCP was performed at the dark cycle $\left(20{ }^{\circ} \mathrm{C}\right.$ and $70 \%$ humidity) in the chamber. Immediately before treatment, three tablets of the 1-MCP product were placed in a small beaker to release 1-MCP gas into plants grown in pots. The pots were placed together with the beaker in a $12-\mathrm{cm}^{3}$ glass box while the box was sealed immediately after treatment. Therefore, the final concentration of gaseous 1-MCP was $0.225 \mu \mathrm{L} \mathrm{L}^{-1}$ applied to plants under this experiment condition. Plant treatments with 1-MCP and PBZ were maintained for $6 \mathrm{~h}$, and subsequently, photosynthesis and EXP expression in leaves and plant growth were determined.

\section{Statistical analysis}

All experiments were carried out at least three times with similar results. Quantitative data were analyzed with the IBM SPSS19.0 software package (IBM Corporation, Armonk, NY, USA; http://www-01.ibm.com/software/analytics/spss/) according to instructions in a text book that describes in detail the analysis methods using IBM SPSS19.0 (Shi 2012). Homogeneity-of-variance in data from Arabidopsis, tomato, or rice plants treated differently was determined by Levene test, and formal distribution pattern of the data was confirmed by Kolmogorov-Smirnov test and P-P plots. Then, data were analyzed by the ANOVA method along with Fisher's least significant difference (LSD).

\section{Results}

Hpa1-induced plant growth enhancement

For the sake of biological consistency and representativeness, we analyzed Hpa1-induced growth-promoting responses by parallel experiments performed on Arabidopsis as a biological model, tomato in which harpin-induced plant growth enhancement was first observed (Kim and Beer 2000), and rice as it is the host of the Hpa1-producing pathogen (Zhu et al. 2000). An aqueous solution of highly purified Hpa1 protein (Fig. 1) was used to immerse seeds or treat plants by spraying over plant tops. Seeds and plants were treated similarly with pure water or an aqueous solution of EVP prepared similarly as for Hpal (Fig. 1) in the experimental control group.

In Arabidopsis, Hpa1-induced growth enhancement was observed with seedlings grown on the medium (Fig. 2a) or in the potting soil (Fig. 2b) following seed treatment. The application of Hpal to 10-day-old plants in pots also enhanced plant growth in the subsequent 30 days (Fig. 2c). Growth enhancement was quantified as an increase of root growth on the medium (Fig. 2d) and an increase of fresh weight of plants in pots (Fig. 2e). In tomato (Fig. $2 \mathrm{f}-\mathrm{j}$ ) and rice (Fig. 2k-o), Hpa1-induced growth enhancement was observed after treated seeds were incubated on filter papers (Fig. 2f, k) or sown in the potting soil (Fig. 2g, 1). The application of Hpa1 to 10-day-old plants in pots also 


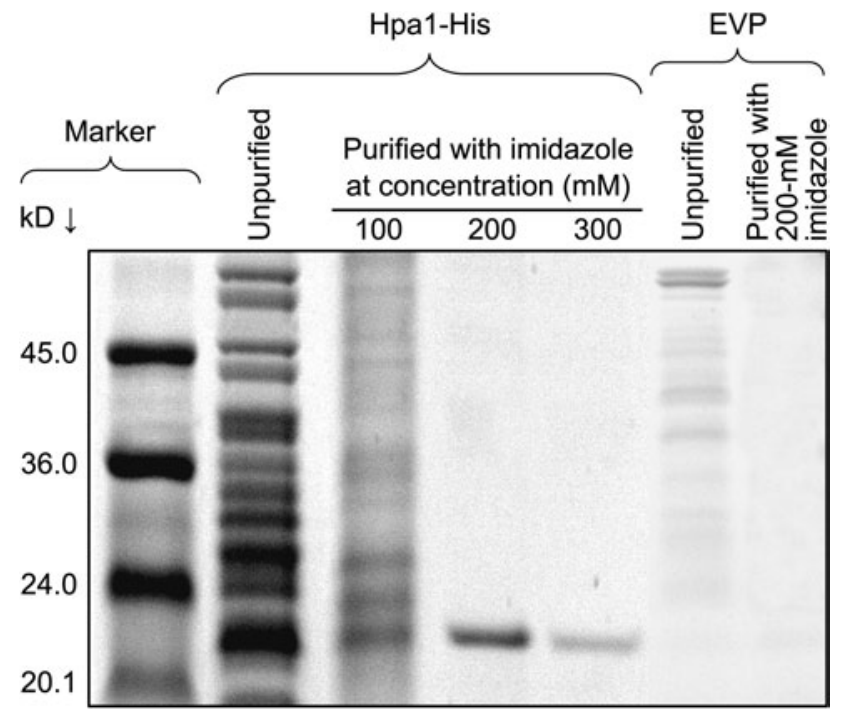

Fig. 1 Protein electrophoresis analysis. The Hpa1-His fusion protein was produced through a recombinant prokaryotic vector and analyzed in comparison with the empty vector preparation (EVP) that did not contain Hpa1-His. Protein samples without purification were analyzed directly by electrophoresis on the tricine-sodium dodecylsulphate-plolyacrylamide gel. Alternatively, protein samples were bound to nickel-polystyrene beads, eluted with the indicated concentrations of imidazole, and then analyzed by electrophoresis. Protein bands were visualized by gel staining with Coomassie G-250. Molecular makers are indicated. The Hpa1-His fusion protein from the 200-mM imidazole eluent was treated with an enterokinase cleavage capture reagent to remove the His tag and only Hpal was used in plant treatment. The 200-mM imidazole eluent of the EVP preparation was used as a negative control

enhanced plant growth in the subsequent 10 days (Fig. 1h, $\mathrm{m})$. Growth enhancement of both tomato and rice was quantified as higher values of height (Fig. 2i, n) and fresh weight (Fig. 2j, o) of 20-day-old plants, tested at day 10 after plant top treatment.

In all plants, differences in growth extents were significant $(P<0.01)$ between the Hpal treatment and the treatment with water or EVP. In Arabidopsis, the Hpa1 treatment caused a 1.9-fold increase in root length of seedlings grown on the medium (Fig. 2d) and a 1.7-fold increase in fresh weight of plants grown in pots (Fig. 2e). In tomato, the multiple of increase in plant height was 1.2 (Fig. 2i) and the multiple of increase in fresh plant weight were 3 (Fig. 2j) following the plant treatment with Hpal compared to EVP or water. In rice, the Hpa1 treatment caused a 2.4-fold increase in plant height (Fig. 2n) and a 2.5-fold increase fresh plant weight (Fig. 2o).

Hpa1-induced physiological responses related to plant growth

To reveal the physiological basis of Hpa1-induced plant growth enhancement, we analyzed the effects of Hpal on nitrogen and chlorophyll concentrations and $A_{\mathrm{N}}$ rates in leaves of Arabidopsis, tomato, and rice. Among the many influencing factors, nitrogen is the most limiting resource for plant growth, and about $80 \%$ nitrogen in leaves is deposited in chloroplast, an organ functioning as a center of biosynthesis and productivity. Measurement values of total nitrogen content in Hpa1-treated Arabidopsis plants was $1.89 \pm 0.21 \mathrm{mg} \mathrm{g}^{-1}$ fresh leaf, counting for a $43.2 \%$ increase compared to the measurement value of $1.32 \pm 0.17 \mathrm{mg} \mathrm{g}^{-1}$ fresh leaf in control plants. Total nitrogen content in leaves of Hpa1-treated tomato plants was $5.54 \pm 0.29 \mathrm{mg} \mathrm{g}^{-1}$ fresh leaf, and this value was $36.5 \%$ greater than that $\left(4.06 \pm 0.43 \mathrm{mg} \mathrm{g}^{-1}\right.$ fresh leaf $)$ in control plants. Similarly, values of total nitrogen content in Hpa1-treated rice plants were $7.21 \pm 0.36 \mathrm{mg} \mathrm{g}^{-1}$ fresh leaf, counting for a $25.4 \%$ increase compared to the measurement value of $5.75 \pm 0.21 \mathrm{mg} \mathrm{g}^{-1}$ fresh leaf in control plants. In all plants, nitrogen concentrations were significantly $(P<0.01)$ increased by the treatment with Hpal compared to water or EVP.

We determined the chlorophyll level since elevation in leaf nitrogen from a moderate level of basal content may promote photosynthesis, which depends on the function of chlorophylls and correlates with leaf chlorophyll content to a certain extent (Yang et al. 2003). In Arabidopsis and tomato plants, levels of total chlorophylls and chlorophyll a were increased significantly $(P<0.01)$ by the treatment with Hpa1 compared to water or EVP, and the Hpa1 treatment caused a slight increase in the content of chlorophyll b (Fig. 3a). In the three plants, moreover, the Hpal treatment significantly $(P<0.01)$ increased the chlorophyll $\mathrm{a} / \mathrm{b}$ ratio (Fig. 3b). Because the chlorophyll a/b ratio correlates with functional maturity of the photosynthetic apparatus and with the photosynthetic activity (Kourill et al. 1999), the observed increase of the ratio indicates that photosynthesis may be promoted by the Hpal treatment.

This hypothesis was confirmed by measurements of $A_{\mathrm{N}}$ rates. Values of $A_{\mathrm{N}}$ in leaves of Arabidopsis, tomato, and rice plants were significantly $(P<0.01)$ increased by the Hpa1 treatment compared to control (Fig. 4). Multiple values of Hpa1-increased $A_{\mathrm{N}}$ rates were 1.9 in Arabidopsis, 1.7 in tomato, and 2.0 in rice. This analysis and analyses of nitrogen and chlorophyll together suggest that increased photosynthesis is an important physiological change associated with Hpa1-induced plant growth enhancement.

Hpa1-enhanced expression of EXP genes required for plant growth

To reveal the molecular basis of Hpa1-induced plant growth enhancement, we determined EXP gene expression in Hpa1-treated and control plants. Based on published sequences, we studied five and three EXP genes of 


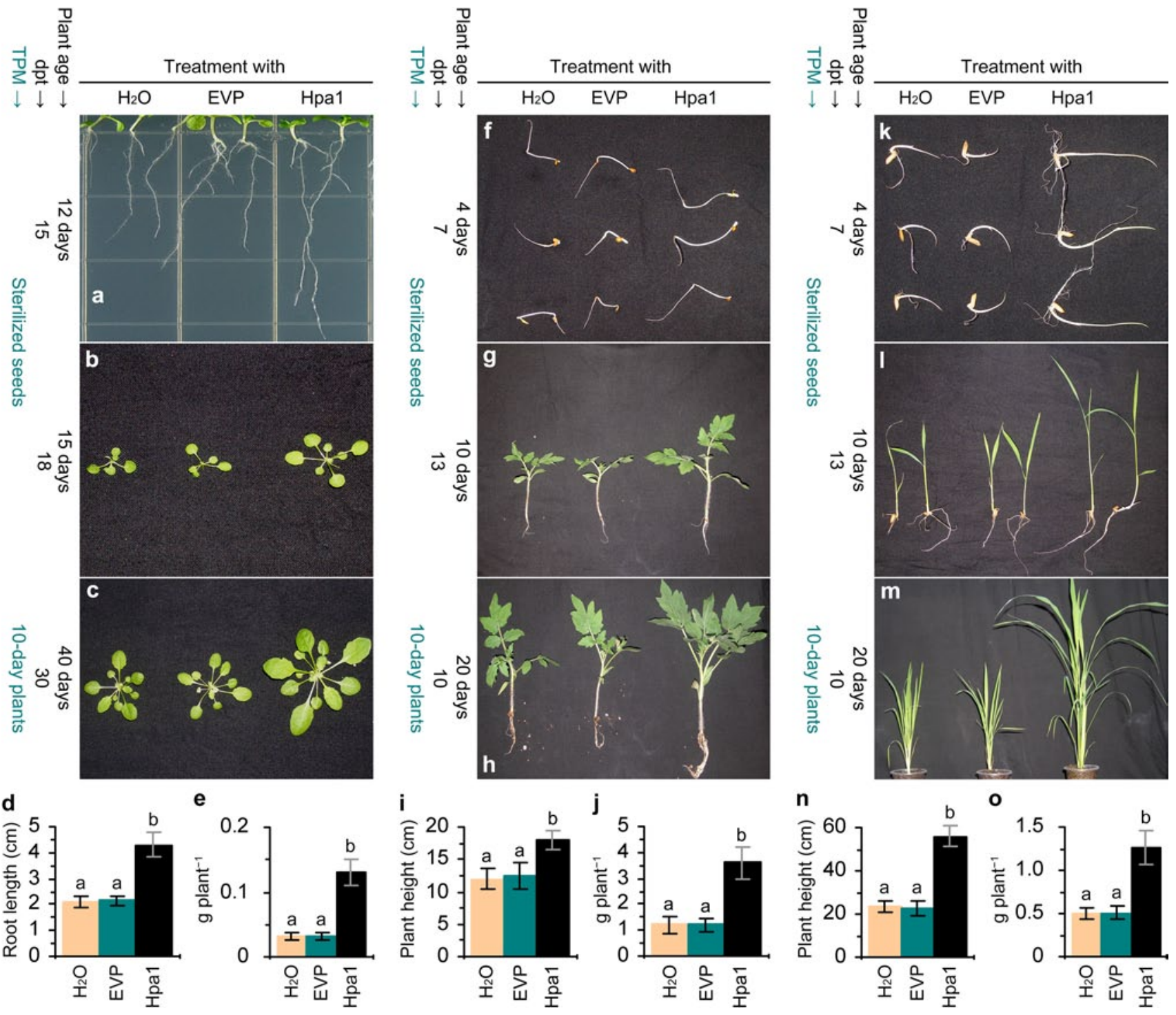

Fig. 2 Hpa1-induced growth enhancement of Arabidopsis (a-e), tomato $(\mathbf{f}-\mathbf{h})$, and rice $(\mathbf{k}-\mathbf{m})$. Pure water and aqueous EVP and Hpal solutions were used separately to treat seeds by immersion or treat plants by spraying over plant tops. "TPM" refers to treated plant material, either sterilized seeds or 10-day-old seedlings; "dpt" denotes days posttreatment; "plant age" is the count of days after seed germination. Results shown in every treatment and plant species combination represent four experimental repeats and a total of 80 plants (20 plants per repeat). a Arabidopsis seedlings photographed at day 15 after treated seeds were inoculated on the medium. b Arabidopsis seedlings photographed at day 18 after treated seeds were inoculated on the potting soil. c Forty-day-old Arabidopsis

Arabidopsis and tomato, respectively. These genes exhibited steady-state expression in control plants but their expression was highly enhanced by Hpal and increased with time in 4 days after the Hpal treatment (Supplementary Fig. S1). AtEXP10 and LeEXP2 were expressed at the most substantial extents in Arabidopsis and tomato, respectively. The expression of both genes reached the highest plants from pots and photographed at day 30 after treatment. d Root length of Arabidopsis seedlings from a. e Fresh weight of Arabidopsis plants from d. Quantitative data shown in bar graphs are mean values \pm standard deviation (SD) bars. $\mathbf{f}, \mathbf{k}$ Tomato (f) and rice (k) seedlings photographed at day 7 after treated seeds were incubated on wet filter papers. g, I Tomato (g) and rice (l) seedlings photographed at day 13 after treated seeds were incubated in potting soil. $\mathbf{i}, \mathbf{j}, \mathbf{n}, \mathbf{o}$ Biomass of tomato $(\mathbf{i}, \mathbf{j})$ from $\mathbf{h}$ and rice $(\mathbf{n}, \mathbf{o})$ from $\mathbf{m}$. Data shown in bar graphs (bottom panels) are mean values \pm standard deviation bars, and different letters on SD bars indicate significant differences analyzed by two-tailed ANOVA and Fisher's least significant difference (LSD) test $(P<0.01)$

levels in $24 \mathrm{~h}$ compared to other time points in 4 days after the Hpa1 treatment (Supplementary Fig. S1). In 24 h, levels of AtEXP10 and LeEXP2 expression in Hpa1-treated plants were increased significantly $(P<0.01)$ and were approximately five times of the steady-state expression level, which was detected in control plants or in Hpa1-treated plants immediately after treatment (Fig. 5). In accordance 

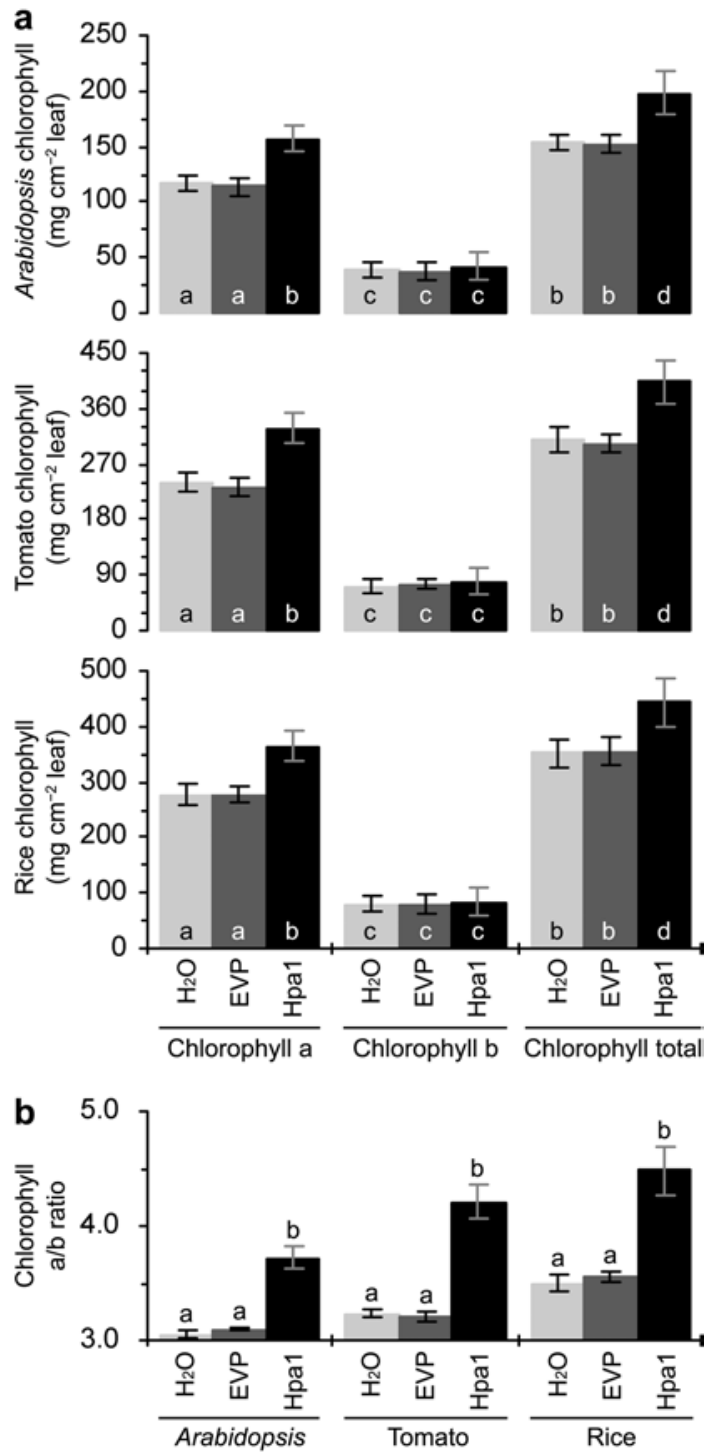

Fig. 3 The effects of Hpa1 on chlorophyll a and b concentrations (a) and chlorophyll a/b ratio (b) in leaves of Arabidopsis, tomato, and rice. Ten-day-old plants grown in pots were treated by spraying over tops separately with an aqueous Hpal solution and with pure water or an aqueous EVP solution in the experimental control group. Five days later, chlorophyll measurements were performed on the second youngest leaves. Data are shown as mean values \pm SD from three experimental repeats (15 plants per repeat). Different letters in bar graphs indicate significant differences by two-tailed ANOVA and LSD test $(P<0.01)$

with our previous studies (Ren et al. 2006a, b; Chen et al. 2008a), moreover, enhanced expression of OSEXP1 (Fig. 5 and Supplementary Fig. S1) was found to be associated with growth enhancement (Fig. 1g-i) of rice plants following treatment with Hpa1. Therefore, enhanced expression of AtEXP10, LeEXP2, and OsEXP1 were used as a molecular marker of Hpa1-induced plant growth enhancement.

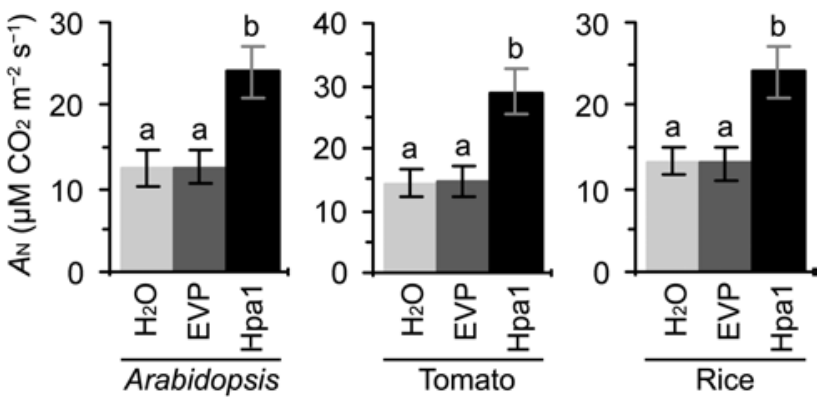

Fig. 4 The effect of Hpal on photosynthesis in leaves of Arabidopsis, tomato, and rice. Ten-day-old plants grown in pots were treated by spraying over tops separately with an aqueous Hpa1 solution and with pure water or an aqueous EVP solution. Five days later, measurements of net photosynthesis $\left(A_{\mathrm{N}}\right)$ rates were performed on the second youngest leaves. Data are shown as mean values \pm SD from three experimental repeats (15 plants per repeat). Different letters on SD bars indicate significant differences by two-tailed ANOVA and LSD test $(P<0.01)$
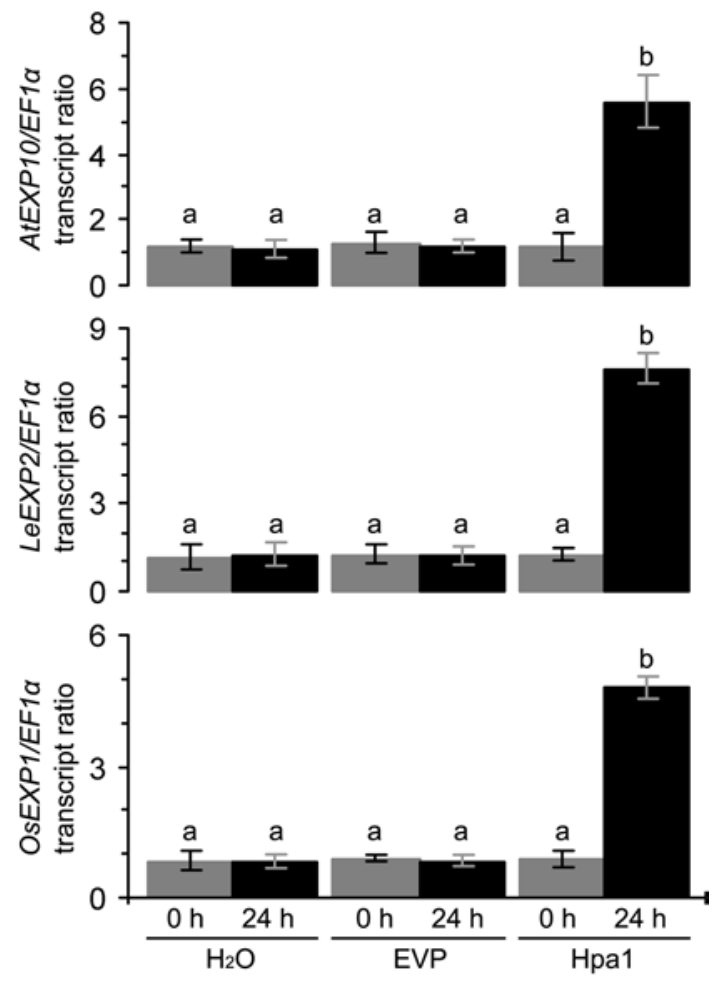

Fig. 5 The effect of Hpa1 on the expression of EXP genes in Arabidopsis, tomato, and rice. Ten-day-old plants grown in pots were treated by spraying over tops separately with an aqueous Hpa1 solution and with pure water or an aqueous EVP solution. Total RNA was isolated from the second youngest leaves and analyzed by real-time reverse transcriptase-polymerase chain reaction (RT-PCR). Amounts of EXP transcripts were quantified in relative to that of $E F 1 \alpha$, a constitutively expressed gene used as a reference. Data are shown as mean values $\pm \mathrm{SD}$ from three experimental repeats (15 plants per repeat). Different letters on SD bars indicate significant differences by two-tailed ANOVA and LSD test $(P<0.01)$ 
Hpa1-enhanced production of ethylene and gibberellin in plants

In order to correlate Hpa1-induced plant growth enhancement with the production of ethylene and gibberellin, we determined the amount of ethylene released from Arabidopsis, tomato, and rice plants and the production of gibberellin in three plants following treatment with Hpal vs. water and EVP. Results are provided in Fig. 6. In water-treated or EVPtreated control plants, the amount of ethylene released and the endogenous concentration of total gibberellin changed little in $12 \mathrm{~h}$. By contrast, the Hpa1 treatment caused significant $(P<0.01)$ increases in ethylene release and total gibberellin content in Arabidopsis, tomato, and rice. In the three plants treated with Hpa1, ethylene was increased by more than twice and gibberellin was increased approximately by 4 folds in contrast to the hormone levels in control plants.

The activation of plant ethylene signaling by Hpa1

To address whether ethylene signaling is involved in Hpa1-induced plant growth enhancement, we analyzed the a

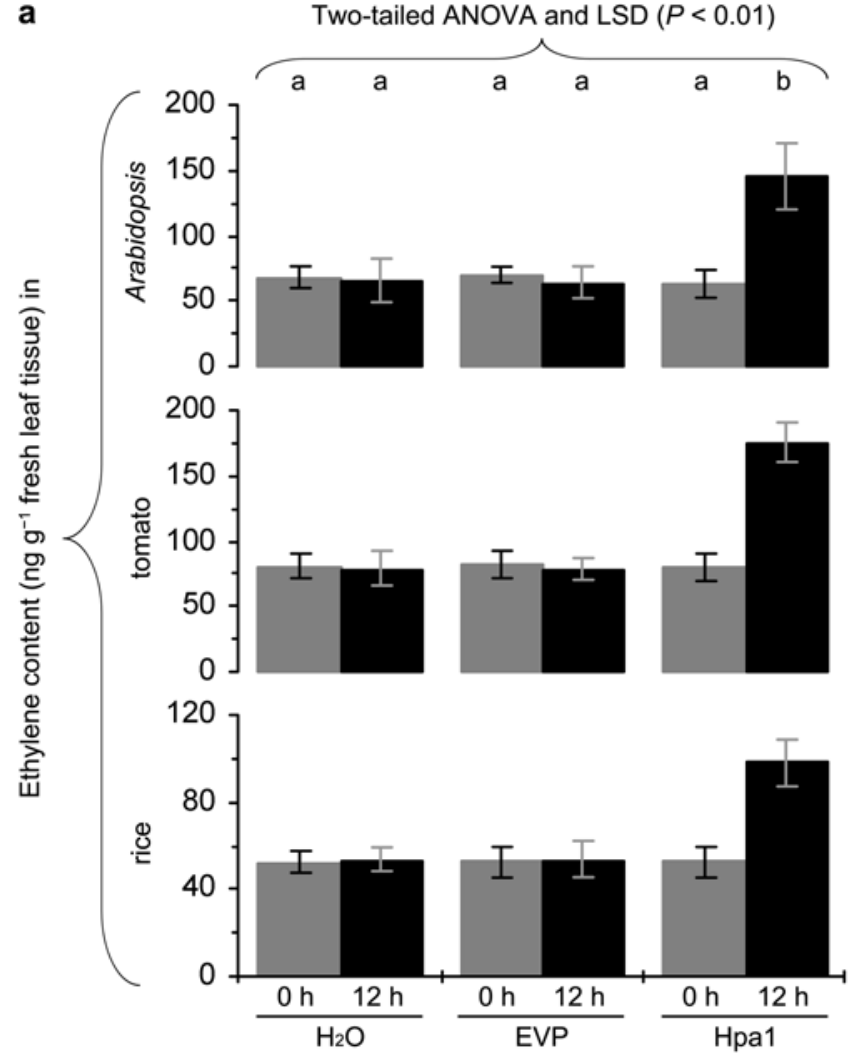

b Arabidopsis plants following treatment with water, EVP, and Hpa1, respectively. The four genes represent three major steps of ethylene signal transduction. First, the ETRI gene encodes ethylene receptor protein ETR1 essential for perception of the ethylene signal and its subsequent transduction to the expression of ethylene-responsive genes (Gamble et al. 2002). ETR1 is also required for Arabidopsis growth enhancement by the $\mathrm{HrpN}_{\mathrm{Ea}}$ harpin from Erwinia amylovora, the pathogen that causes fire blight in rosaceous plants (Dong et al. 2004). In Hpa1-treated plants, ETRI was expressed $6 \mathrm{~h}$ after treatment and expression level was increased with time in the subsequent $90 \mathrm{~h}$ (Supplementary Fig. S2). Inversely, ETR1 expression was not detected in control plants. Second, the EIN5 gene encodes an exoribonuclease (Olmedo et al. 2006; Potuschak et al. 2006), which is an essential component of the ethylene signaling pathway and regulates plant growth enhancement by Hrp$\mathrm{N}_{\text {Ea }}$ (Dong et al. 2004). The EIN5 gene had a steady-state level of expression in control plants; whereas, its expression level was enhanced in Hpa1-treated plants and increased

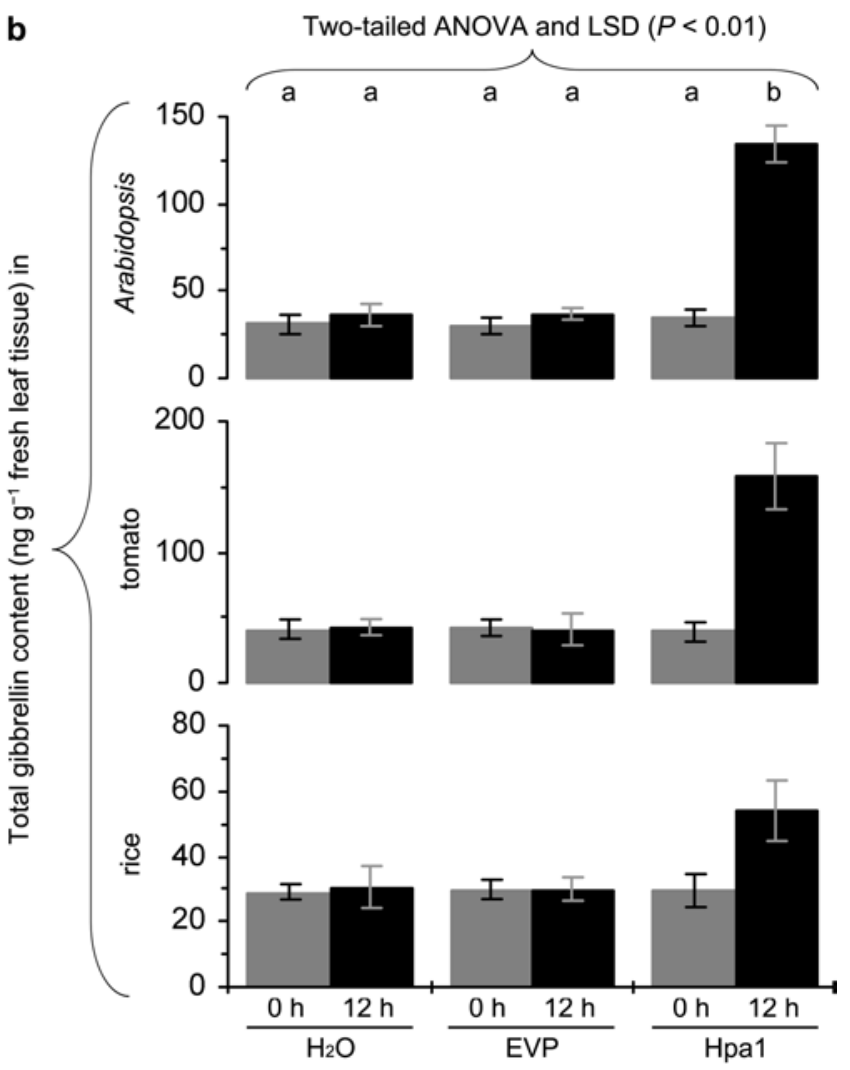

and ethylene-responsive genes $(P D F 1.2$ and $P R-3 b)$ in

Fig. 6 The effects of Hpal on concentrations of phytohormones ethylene (a) and gibberellin (b) in Arabidopsis, tomato, and rice plants. Ten-day-old plants grown in pots were treated by spraying over tops separately with an aqueous Hpal solution and with pure water or an aqueous EVP solution. Concentrations of both hormones were

determined at the indicated time points. Data are shown as mean values \pm SD from three experimental repeats (15 plants per repeat). Different letters on tops of bar graphs indicate significant differences by the statistical analysis 
with time in 6-96 h after treatment (Supplementary Fig. S2). Third, the PDF1.2 and $P R-3 b$ genes are molecular markers of the ethylene signaling pathway (Pieterse et al. 1998; Penninckx et al. 1998). Both genes were expressed only in Hpa1-treated plants (but not in water-treated or EVP-treated control plants) and accumulated transcripts detectable by RT-PCR at hour 12 after the Hpa1 treatment and increased expression levels in next $84 \mathrm{~h}$ (Supplementary Fig. S2). These analyses indicate that the ethylene signaling pathway is activated by the Hpa1 treatment.

The role of ethylene in Hpa1-enhanced photosynthesis, EXP expression, and plant growth

To elucidate whether ethylene signaling plays a role in Hpa1-enhanced photosynthesis, EXP expression, and plant growth, we first analyzed these responses in the wild-type
(WT) plant of Arabidopsis and its mutant etrl-1, which has a defect in ETR1 and fails to sense and transmit the ethylene signal (Schaller and Bleecker 1995; Gamble et al. 2002). We found that photosynthesis was diminished in etr $1-1$ compared to WT (Fig. 7a). The mutant was impaired in normal photosynthesis as indicated by a lower value of the $A_{\mathrm{N}}$ rate relative to that of WT detected in control (treatment with water or EVP). The mutant was further impaired in the promoting effect of Hpal on photosynthesis, and Hpa1-increased percentage of the $A_{\mathrm{N}}$ rate over the rate in control was $92 \%$ in WT and $48 \%$ in etrl-1. In the mutant, AtEXP10 expression and the enhancement by Hpal were compromised concomitantly (Fig. 7b). Hpa1-increased part of AtEXP10 expression was diminished by $47 \%$, but not canceled totally. In etr1-1, moreover, normal growth and Hpa1-induced growth enhancement were both impaired (Fig. 7c). The Hpal treatment caused increases of fresh
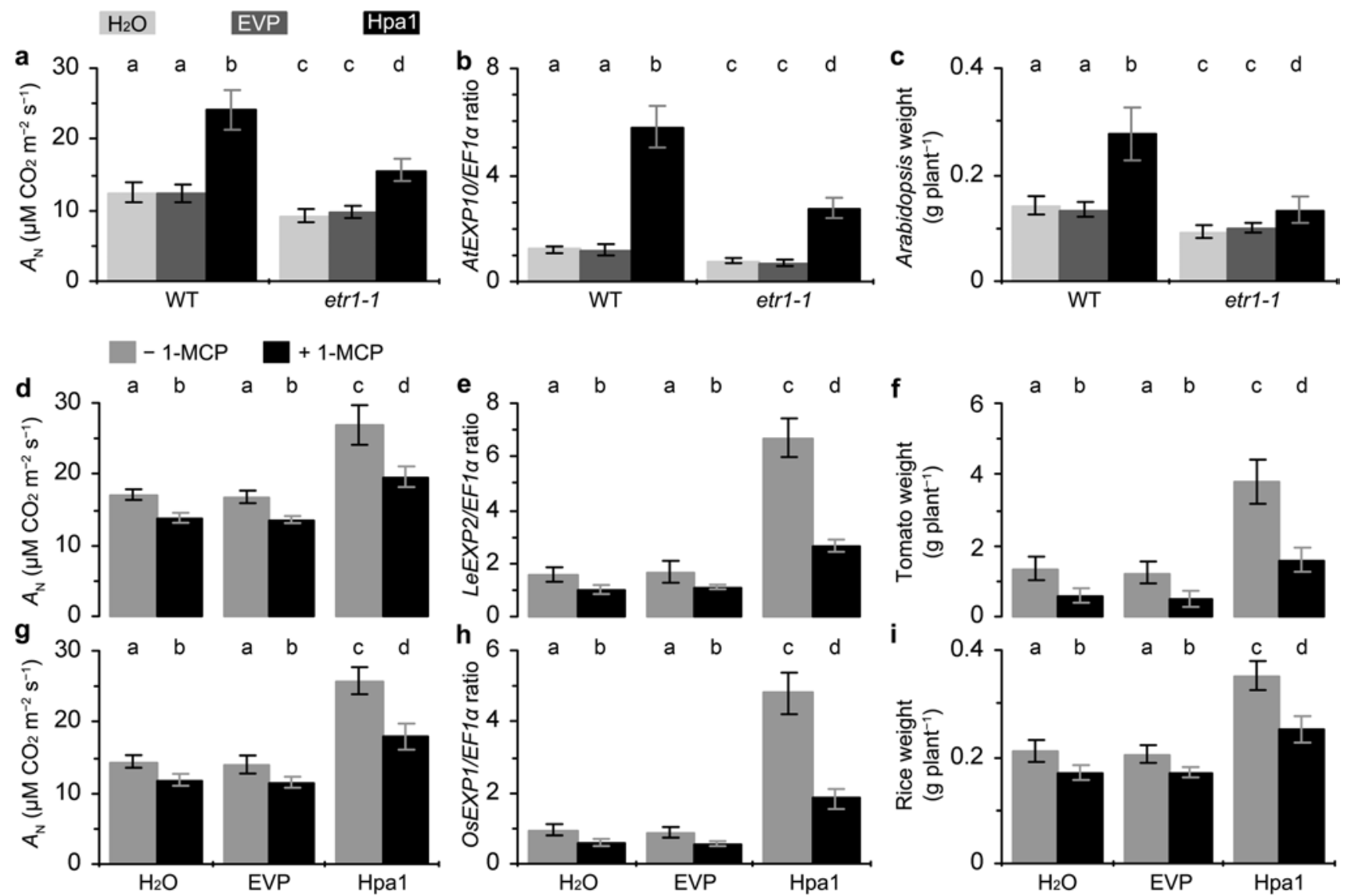

Fig. 7 The inhibitory effects of genetic or chemical blocking in ethylene perception on Hpa1-induced enhancements of photosynthesis, EXP expression, and plant growth. a-c The Arabidopsis mutant etrl1, which has a defect in the ethylene receptor ETR 1 and fails to sense and transmit the ethylene signal, was tested together with the wildtype (WT) plant in the experiments. Ten-day-old plants were treated separately with an aqueous Hpal solution and with pure water or an aqueous EVP solution. d-i The ethylene signaling inhibitor 1-methylcyclopropene (1-MCP) was used to block ethylene signal transduc- tion in tomato $(\mathbf{d}-\mathbf{f})$ and rice $(\mathbf{g}-\mathbf{i})$ plants. Ten-day-old plants were treated with water or aqueous EVP and Hpa1 solutions in the presence of 1-MCP (+1-MCP) and the absence of 1-MCP (-1-MCP). a-i Five days after plant treatment, analyses of $A_{\mathrm{N}}$ rates and $E X P$ expression were performed on the second youngest leaves. Fresh weight of plants was scored 10 days after treatment. Data are shown as mean values \pm SD from three experimental repeats (15 plants per repeat). Different letters on tops of bar graphs indicate significant differences by the statistical analysis 
plant weight by $93 \%$ in WT and $53 \%$ in etrl-1, indicating that Hpa1-induced growth enhancement was diminished but not totally canceled by the genetic blocking of ethylene perception in the mutant.

We treated tomato (Fig. 7d-f) and rice (Fig. 7g-i) plants with the ethylene signaling inhibitor 1-MCP, which was used in an aqueous Hpal solution and with pure water or EVP in control. We found that the pharmacological effects of 1-MCP resembled the genetic effects of etrl-1 on photosynthesis (Fig. 7d, g), EXP expression (Fig. 7e, h), plant growth (Fig. 7f, i), and enhancements of these events by Hpa1 (Fig. 7d-i). The application of 1-MCP to inhibit ethylene signaling only diminished, but did not completely eliminate, Hpa1-induced plant growth enhancement and associated enhancements in photosynthesis and EXP expression (Fig. 7d-i). This result and the analysis of etr 1-1 together indicate that ethylene signaling plays a partial role in regulating Hpa1-enhanced plant growth and the associated responses.

The role of gibberellin in Hpa1-enhanced photosynthesis, EXP expression, and plant growth

To elucidate the role of gibberellin in Hpa1-enhanced photosynthesis, EXP expression, and plant growth, the Arabidopsis ga5-1 mutant, which is defective in gibberellin biosynthesis (Xu et al. 1995; Sponsel et al. 1997), was tested together with the WT plant in responses to the Hpal treatment. We found that photosynthesis was diminished in ga51 compared to WT (Fig. 8a). The mutant was impaired in normal photosynthesis as indicated by a lower value of the $A_{\mathrm{N}}$ rate relative to that of WT detected in control (treatment
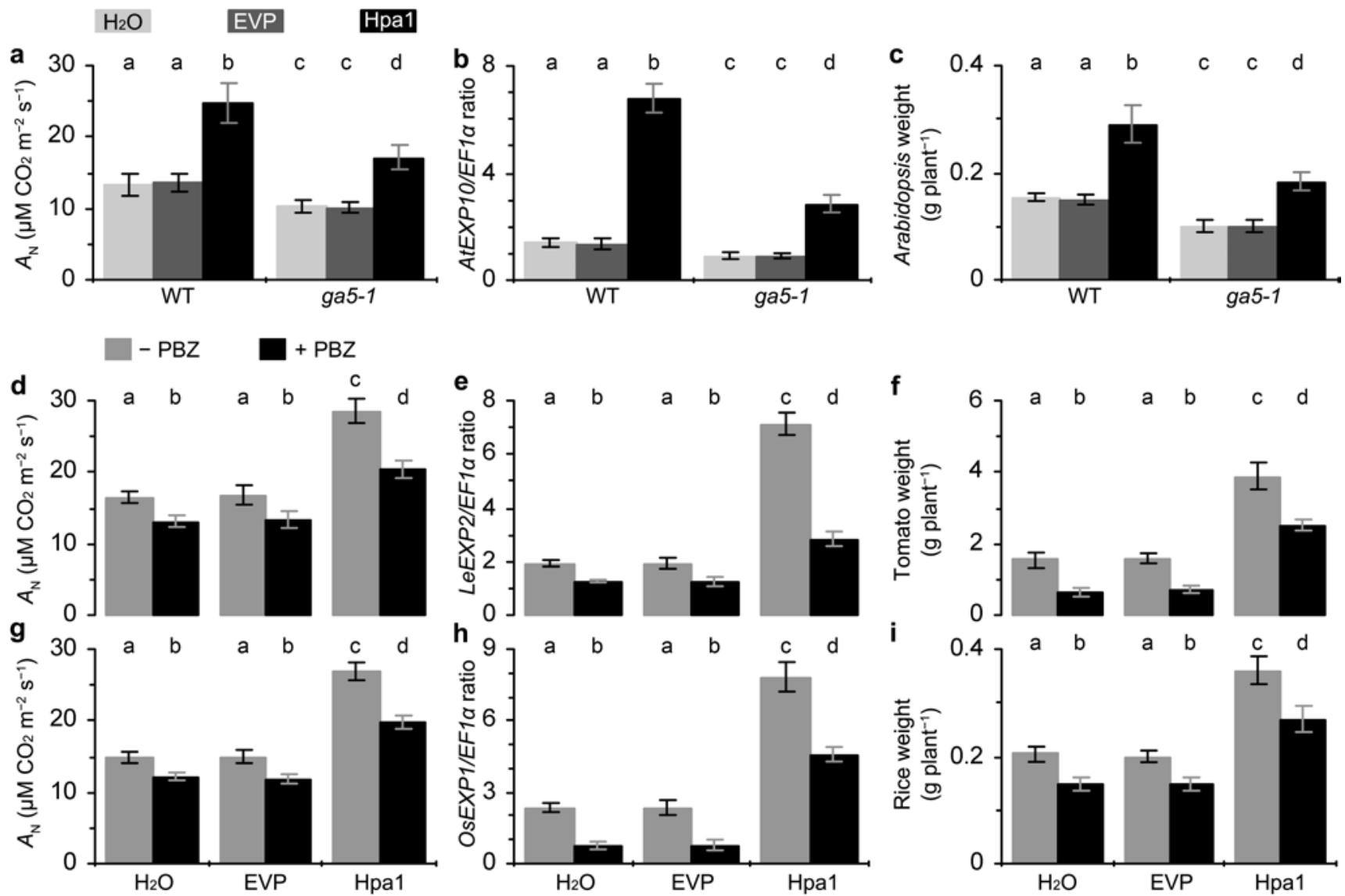

Fig. 8 The inhibitory effects of genetic or chemical blocking in gibberellin biosynthesis on Hpa1-induced enhancements of photosynthesis, EXP expression, and plant growth. a-c The Arabidopsis mutant ga5-1, which has a defect in gibberellin biosynthesis, was tested together with the WT plant in the experiments. Ten-day-old plants were treated separately with an aqueous Hpal solution and with water or an aqueous EVP solution. d-i The gibberellin biosynthesis inhibitor PBZ was used to inhibit gibberellin biosynthesis in tomato $(\mathbf{d}-\mathbf{f})$ and rice $(\mathbf{g}-\mathbf{i})$ plants. Ten-day-old plants were treated separately with Hpa1 and Silwet-37 in the presence of PBZ $(+$ PBZ) and the absence of PBZ (-PBZ). a-i Five days after plant treatment, analyses of $A_{\mathrm{N}}$ rates and EXP expression were performed on the second youngest leaves. Fresh weight of plants was scored 10 days after treatment. Data are shown as mean values \pm SD from three experimental repeats (15 plants per repeat). Different letters on tops of bar graphs indicate significant differences by two-tailed ANOVA and LSD test $(P<0.01)$ 
with water or EVP). The mutant was further impaired in the promoting effect of Hpa1 on photosynthesis, and Hpa1increased percentage of the $A_{\mathrm{N}}$ rate over the rat in control was $98 \%$ in WT and $53 \%$ in ga5-1. In the mutant, AtEXP10 expression and the enhancement by Hpal were compromised concomitantly (Fig. 8b). Hpa1-increased part of AtEXP10 expression was diminished by $47 \%$ but not canceled totally. In ga5-1, moreover, normal growth and Hpa1-induced growth enhancement were both impaired (Fig. 8c). The Hpa1 treatment caused increases of fresh plant weight by $96 \%$ in WT and $48 \%$ in etrl-1, indicating that Hpa1-induced growth enhancement was diminished but not totally canceled in the mutant.

We then investigated responses of tomato (Fig. 8d-f) and rice (Fig. 8g-i) plants to the gibberellin biosynthesis inhibitor PBZ, which was applied together with Hpa1, water, or EVP. We found that the pharmacological effects of PBZ resembled the genetic effects of ga5-1 on photosynthesis (Fig. 8d, g), EXP expression (Fig. 8e, h), and plant growth (Fig. 8f, i), and enhancements of these events by Hpa1 (Fig. 8d-i). Therefore, the application of PBZ to inhibit gibberellin synthesis only diminished, but did not completely eliminate, Hpa1-induced plant growth enhancement, and associated enhancements in photosynthesis and EXP expression. This result is consistent with the analysis of ga5-1, indicating that Hpa1-enhanced plant growth and the associated responses are partially regulated by gibberellin.

The interactive role of ethylene and gibberellin in Hpa1-enhanced photosynthesis, EXP expression, and plant growth

To analyze whether ethylene and gibberellin coregulate Hpa1-enhanced photosynthesis, EXP expression, and plant growth, we generated the Arabidopsis etrl-1 ga5-1 double mutant and characterized it based on nullified expression of both ETR1 and GA5 genes (Supplementary Fig. S3a), etrl-1-caused ethylene insensitivity in triple response (Supplementary Fig. S3b; Guzmán and Ecker 1990), and ga51-caused gibbrellin insensitivity in the silique development (Supplementary Fig. S3c; Vivian-Smith and Koltunow 1999). We compared the double mutant with the single mutants and the WT plant in terms of photosynthesis, EXP expression, and plant growth enhanced by Hpal compared to water or EVP. We confirmed that the promoting effects of Hpal on photosynthesis (Fig. 9a), AtEXP10 expression (Fig. 9b), and plant growth (Fig. 9b) were partially eliminated in etrl-1 or ga5-1 compared to WT. We further found that all the effects of Hpal were canceled completely in etrl-1 ga5-1, which had similar levels of photosynthesis, AtEXP10 expression, and growth irrespective of treatment with Hpa1 or Silwet-37 (Fig. 9a-c).
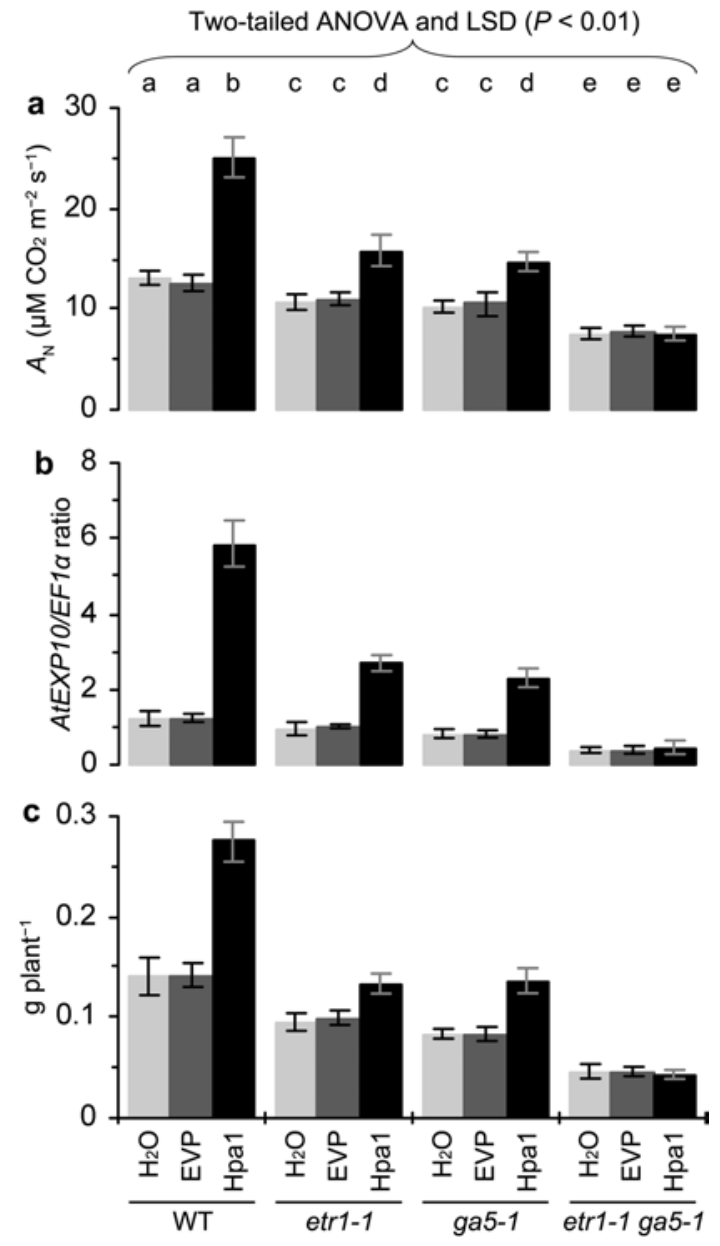

Fig. 9 Genetic analysis for combinative effects of ethylene and gibberellin on Hpal-enhanced photosynthesis, EXP expression, and growth of Arabidopsis. The WT plant, etr1-1 and ga5-1 single mutants, and etrl-1 ga5-1 double mutant were tested in the experiments. Ten-day-old plants were treated separately with an aqueous Hpa1 solution and with pure water or an aqueous EVP solution. Five days later, analyses of $A_{\mathrm{N}}$ rates and EXP expression were performed on the second youngest leaves. Fresh weight of plants was scored 10 days after treatment. Data are shown as mean values \pm SD from three experimental repeats (15 plants per repeat). Different letters on bar graphs indicate significant differences by the statistical analysis

We performed a genetic and chemical combinative analysis on WT and etrl-1 plants by treating them separately with Hpa1, water, and EVP in the presence or absence of PBZ. This assay confirmed that the promoting effect of Hpal on photosynthesis, and plant growth were partially removed by the application of PBZ or in the etrl-1 mutant compared to the WT plant (Fig. 10a). Noticeably, all the effects of Hpa1 were totally eliminated in the mutant following treatment with PBZ (Fig. 10a).

We assayed photosynthesis, AtEXP10 expression, and growth of ga5-1 and WT plants following treatment with Hpa1, water, or EVP in the presence and absence of 1-MCP, respectively. While the presence of 1-MCP 

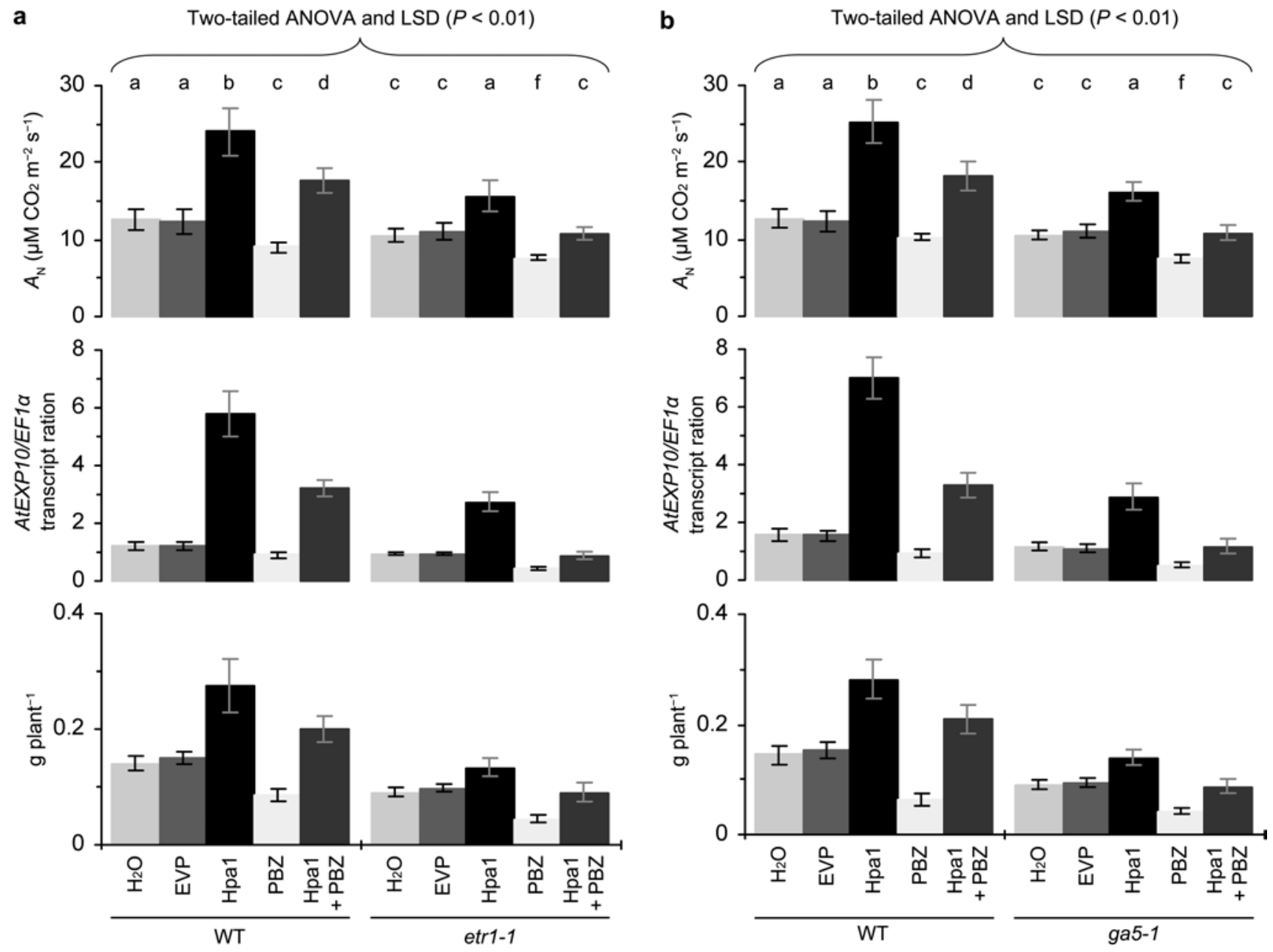

Fig. 10 Genetic and chemical analyses for the interactive effects of ethylene and gibberellin on Hpa1-enhanced photosynthesis, EXP expression, and growth of Arabidopsis. a Ten-day-old WT and etrl-1 plants were treated separately with pure water or an aqueous EVP solution and with aqueous solutions of Hpa1, PBZ, and a Hpa1 + PBZ mixture. b Ten-day-old WT and ga5-1 plants were treated separately with pure water or an aqueous EVP solution and

diminished the effects of Hpal in the WT plant, 1-MCP applied to the ga5-1 mutant totally eliminated all the effects of Hpa1 (Fig. 10b).

Taken together, these analyses indicate that ethylene and gibberellin indeed cooperate to regulate Hpa1-induced plant growth enhancement and the associated responses at physiological and molecular levels.

\section{Discussion}

Harpin-induced plant growth enhancement was well demonstrated (Dong et al. 2004; Liu et al. 2006; Ren et al. 2006a, b, 2008; Oh and Beer 2007; Wu et al. 2007; Chen et al. 2008a, b), but the physiological and molecular with aqueous solutions of Hpa1, 1-MCP, and a Hpa1 + 1-MCP mixture. a, b Five days after plant treatment, analyses of $A_{\mathrm{N}}$ rates and EXP expression were performed on the second youngest leaves. Fresh weight of plants was scored 10 days after treatment. Data shown are mean values \pm SD from three experimental repeats (15 plants per repeat). Different letters on bar graphs indicate significant differences by the statistical analysis

mechanisms were not concomitantly elucidated. In this study, we utilize the purified Hpal protein (Fig. 1) as a model of harpins and characterize in detail the phenotype of Hpa1-induced plant growth enhancement (Fig. 2) in correlation with growth-promoting responses, including photosynthesis and related physiological responses (Figs. 3, 4), as well as the expression of EXP genes, especially AtEXP10 and LeEXP2 (Fig. 5; Supplementary Fig. S1) in Arabidopsis, tomato, and rice plants.

Substantial levels of EXP expression detected in 4 days after the plant treatment with the Hpal protein (Supplementary Fig. S1) indicate the stable effect of the protein. The stable effect of Hpal may be related to the stability of the protein in the plant. Harpin orthologs from different bacterial species (Choi et al. 2013) are conservatively 
sensitive to proteases (Wei et al. 1992; Kim and Beer 2000) and have the possibility of fast hydrolysis by plant proteases. If the hydrolysis occurs, it should impair the effects of harpins in plants. However, the relationship between the effects of harpins and their stability in plant was not directly elucidated in approximately 220 papers relating to harpins published since 1992. Based on the structuralfunctional relationship of harpins and their recognition by plant cells, we assume that the multiple effects of Hpal in plants (Peng et al. 2004; Liu et al. 2006; Ren et al. 2006a, b; Wu et al. 2007; Chen et al. 2008a; Sang et al. 2012) are guaranteed by three possible mechanisms.

Firstly, certain functional regions in the Hpa1 protein sequence (Liu et al. 2006; Wang et al. 2007, 2008; Chen et al. 2008a, b; Ji et al. 2011) allow its functions to perform in the case of hydrolysis within plant. If Hpa1 veritably undergoes a quick degradation, functional fragments of the protein are likely to resemble the full length in inducing plant growth enhancement and defense responses. The dual role of Hpal does not necessarily require full length of the protein, but instead, certain regions of the total protein sequence are more active experimentally (Wu et al. 2007; Chen et al. 2008a). For example, the 10-42-residue fragment $\left(\mathrm{Hpa}_{10-42}\right)$ isolated from the Hpal sequence is 1.3-7.5-fold more effective than the full length in inducing growth enhancement and defense responses in tea, tobacco, and rice as tested so far (Wu et al. 2007; Chen et al. 2008a, b). If Hpal veritably incurs a fast degradation in plant, the resulting fragments, such as $\mathrm{Hpa}_{10-42}$ or containing Hpal $_{10-42}$ may be still active.

Secondly, harpin protein stability provides sufficient time for plant responses and harpin protein binding to plant cells (Oh and Beer 2007; Sang et al. 2012; Choi et al. 2013), probably reducing the possibility of hydrolysis. In this case, a stable activity for a certain period of time may be sufficient to induce plant responses. In a sole study about harpin protein stability, an unpurified $\mathrm{HrpN}_{\mathrm{Ea}}$ preparation lost all bioactivity after $3 \mathrm{~h}$ at $37{ }^{\circ} \mathrm{C}$ or $6-8 \mathrm{~h}$ at $4{ }^{\circ} \mathrm{C}$; and incubation of $\mathrm{HrpN}_{\mathrm{Ea}}$ with protease type XIV at $100 \mu \mathrm{g} \mathrm{mL}^{-1}$, for $1 \mathrm{~h}$ at $37{ }^{\circ} \mathrm{C}$ destroyed bioactivity and eliminated the protein (Wei et al. 1992). Therefore, $\mathrm{HrpN}_{\mathrm{Ea}}$ must be stable in plant for at least $1 \mathrm{~h}$ because the concentration of any proteases is impossible to be high as $100 \mu \mathrm{g} \mathrm{mL}^{-1}$ outside plant cells where harpins locate (Oh and Beer 2007; Sang et al. 2012; Choi et al. 2013), and because temperature in plant growth environment is unlikely to be high as $37{ }^{\circ} \mathrm{C}$ in most circumstances. The protein stability may be commonly shared by all harpin orthologs since they are conserved in biochemical characteristics (Wei et al. 1992; Kim and Beer 2000; Choi et al. 2013). If this hypothesis is correct, Hpal should be stable for at least $1 \mathrm{~h}$ in plant. This time is sufficient for plant responses (Fig. 6; Supplementary Figs. S1 and S2) even if harpin protein binding to plant cells (Oh and Beer 2007; Sang et al. 2012; Choi et al. 2013) does not increase the stability.

Thirdly, the activation of cellular signaling cascade determines duration of the effect of a harpin protein in plant (Dong et al. 1999, 2004, 2005). Plant sensing of Hpa1 and subsequent cellular responses are fast. Indeed, Hpa1 applied to Arabidopsis binds to the plasma membrane (Sang et al. 2012) and induces a rapid production of plant signaling compounds, such as hydrogen peroxide $\left(\mathrm{H}_{2} \mathrm{O}_{2}\right)$, a cellular signal that mediates many aspects of plant development and defense responses (Nanda et al. 2010; Torres 2010; Sang et al. 2012). In Hpa1-treated Arabidopsis, $\mathrm{H}_{2} \mathrm{O}_{2}$ can be produced in the apoplast within $5 \mathrm{~min}$ and then the apoplastic $\mathrm{H}_{2} \mathrm{O}_{2}$ moves into the cytosol (Sang et al. 2012). The apoplastic production and cytosolic translocation of $\mathrm{H}_{2} \mathrm{O}_{2}$ are responsible for induced resistance to a bacterial pathogen in the plant (Sang et al. 2012). Similarly, the production of ethylene and gibberellin is highly induced within $12 \mathrm{~h}$ following the Hpa1 treatment (Fig. 6). Both hormones play an essential role in Hpal-induced growth enhancement and the associated responses in the plant (Figs. 7, 8, 9, 10).

Previous studies show that ethylene plays a regulatory role in plant growth enhancement by $\mathrm{HrpN}_{\mathrm{Ea}}$ (Dong et al. 2004; Ren et al. 2008), and the present study suggests that Hpal requires both ethylene and gibberellin to induce plant growth enhancement (Figs. 7, 8, 9, 10). We chose to elucidate the role of gibberellin in Hpa1-induced plant growth enhancement and the associated responses based on two considerations: (1) gibberellin is implicated in EXP expression associated with the vegetative growth of plants (Cho and Kende 1997; Vogler et al. 2003); (2) EXP expression is inducible by harpins (at least $\mathrm{Hpal}$ and $\mathrm{HrpN}_{\mathrm{Ea}}$ ) and contributes to harpin-induced plant growth enhancement (Dong et al. 2004; Liu et al. 2006; Ren et al. 2006a, b; Wu et al. 2007; Chen et al. 2008a; Li et al. 2014). Meanwhile, we chose to study the cooperative roles of ethylene and gibberellin in the effects of Hpal on plants because of two reasons: (1) ethylene signaling was shown to be responsible for the phenotype of harpin-induced plant growth enhancement and the induction of EXP expression (Dong et al. 2004; Ren et al. 2008) but whether harpin-enhanced photosynthesis is also subject to ethylene signaling was unclear; (2) it is unclear whether gibberellin participates in the function of harpins in promoting photosynthesis and enhancing EXP expression.

Based on studies by genetic and chemical combinative methods, gibberellin and ethylene perform similarly in response to Hpal and individually plays a partial role in the regulation of Hpa1-enhanced photosynthesis, EXP expression, and plant growth (Figs. 7, 8). In other words, ethylene and gibberellin coregulate the full effects of Hpa1 in plants (Figs. 9, 10). Nevertheless, how both 
hormones are induced and how they regulate the functions of Hpal remain to be studied. The functional networks may be complicated. For instance, $\mathrm{HrpN}_{\mathrm{Ea}}$ induces the protein kinase MPK6 (Desikan et al. 2001), and MPK6 phosphorylates 1-aminocyclopropane-1-carboxylic acid synthase (Liu and Zhang 2004), which is the rate-limiting enzyme and the major regulatory step in stress-induced ethylene production (Bleecker and Kende 2000; Wang et al. 2002). Moreover, photosynthesis relies on cellular $\mathrm{CO}_{2}$ uptake. On the basis of the significant role of $\mathrm{CO}_{2}$ transport across the plasma membrane (Heckwolf et al. 2011; Flexas et al. 2012; Kaldenhoff 2012; Uehlein et al. 2012), the phenotypic-physiological relevance for the Hpal activity may shed light on further characterization of whether and how Hpal is recognized by a protein located on the plasma membrane and of whether a molecular interaction is involved in the function of Hpa1. The postulated molecular interaction on the plasma membrane may be linked to the hormone signaling pathways as harpins (at least $\mathrm{Hpal}$ or $\mathrm{HrpN}_{\mathrm{Ea}}$ ) are localized on the plasma membrane where they trigger a cellular signaling pathway to regulate plant defense responses or growth enhancement (Lee et al. 2001a, b; Oh and Beer 2007; Sang et al. 2012). Evidently, it is a great challenge to elucidate plant sensing of Hpal and subsequent responses that are connected to a cellular pathway of ethylene or gibberellin signal transduction.

The cooperation of ethylene and gibberellin may be specific for plant growth enhancement by a harpin protein since at least salicylic acid and jasmonic acid have been excluded from $\mathrm{HrpN}_{\mathrm{Ea}}$-induced plant growth enhancement (Dong et al. 2004). However, there is as yet no evidence to exclude additional phytohormones, especially auxin, a phytohormone that is as multifunctional as ethylene or gibberellin and regulates many aspects of plant growth and development (Liscum and Reed 2002). Moreover, although harpin orthologs from different bacterial species have been shown to activate the same spectrum of hormone signaling (Strobel et al. 1996; Dong et al. 1999, 2004, 2005; Peng et al. 2004; Chen et al. 2008a; Zhang et al. 2011a, b; Sang et al. 2012), it is still necessary to study in the future whether the cooperative role of ethylene and gibberellin applies to different harpin orthologs in addition to Hpa1.

Acknowledgments This study was supported by grants from the national 973 Plan (grant number 2012CB114003), NSFC (grant numbers 31171830 and 31272072), Novel Transgenic Organisms Breeding Project (grant number 2011ZX08002-001), and Ministry of Education 111 Project of China.

Open Access This article is distributed under the terms of the Creative Commons Attribution License which permits any use, distribution, and reproduction in any medium, provided the original author(s) and the source are credited.

\section{References}

Alfano JR, Collmer A (2004) Type III secretion system effector proteins: double agents in bacterial disease and plant defense. Annu Rev Phytopathol 42:385-414

Beall FD, Morgan PW, Mander LN, Miller FR, Babb KH (1991) Genetic regulation of development in Sorghum bicolor. V. The $m a_{3}^{\mathrm{R}}$ allele results in gibberellin enrichment. Plant Physiol 95:116-125

Bleecker AB, Kende H (2000) Ethylene: a gaseous signal molecule in plants. Annu Rev Cell Dev Biol 16:1-18

Chen L, Qian J, Qu SP, Long J, Yin Q, Zhang C, Wu X, Sun F, Wu T, Beer SV, Dong H (2008a) Identification of specific fragments of $\mathrm{HpaG}_{\mathrm{Xooc}}$, a harpin from Xanthomonas oryzae pv. oryzicola, that induce disease resistance and enhance growth in plants. Phytopathology 98:781-791

Chen L, Qian J, Qu SP, Yin Q, Qian J, Wu X, Sun F, Wu T, Cheng Z, Beer SV, Dong H (2008b) A fragment of the Xanthomonas oryzae pv. oryzicola harpin $\mathrm{HpaG}_{\mathrm{Xooc}}$ reduces disease and increases yield of rice in extensive grower plantings. Phytopathology 98:792-802

Cho HT, Cosgrove DJ (2002) Regulation of root hair initiation and expansin gene expression in Arabidopsis. Plant Cell 14:3237-3253

Cho HT, Kende H (1997) Expression of expansin genes is correlated with growth in deepwater rice. Plant Cell 9:1661-1671

Choi MS, Kim W, Lee C, Oh CS (2013) Harpins, multifunctional proteins secreted by gram-negative plant-pathogenic bacteria. Mol Plant-Microbe Interact 26:1115-1122

Colmer TD, Peeters AJ, Wagemaker CA, Vriezen WH, Ammerlaan A, Voesenek LA (2004) Expression of $\alpha$-expansin genes during root acclimations to $\mathrm{O}_{2}$ deficiency in Rumex palustris. Plant Mol Biol 56:423-437

Cosgrove DJ (2001) Wall structure and wall loosening. A look backwards and forwards. Plant Physiol 125:131-134

Cox MC, Benschop JJ, Vreeburg RA, Wagemaker CA, Moritz T, Peeters AJ, Voesenek LA (2004) The roles of ethylene, auxin, abscisic acid, and gibberellin in the hyponastic growth of submerged Rumex palustris petioles. Plant Physiol 136:2948-2960

Desikan R, Hancock JT, Ichimura K, Shinozaki K, Neill SJ (2001) Harpin induced activation of the Arabidopsis mitogen-activated protein kinases AtMPK4 and AtMPK6. Plant Physiol 126:1579-1587

Ding X, Cao Y, Huang L, Zhao J, Xu C, Li X, Wang S (2008) Activation of the indole-3-acetic acid-amido synthetase GH3-8 suppresses expansin expression and promotes salicylate- and jasmonate-independent basal immunity in rice. Plant Cell 20:228-240

Dong HS, Delaney TP, Bauer DW, Beer SV (1999) Harpin induces disease resistance in Arabidopsis through the systemic acquired resistance pathway mediated by salicylic acid and the NIMI gene. Plant J 20:207-215

Dong HP, Peng JL, Bao ZL, Meng XD, Bonasera JM, Chen GY, Beer SV, Dong HS (2004) Downstream divergence of ethylene signaling pathway for harpin-stimulated Arabidopsis growth and insect defense. Plant Physiol 136:3628-3638

Dong HP, Yu HQ, Bao ZL, Guo XJ, Peng JL, Yao Z, Chen GY, Qu SP, Dong HS (2005) The ABI2-dependent abscisic acid signalling controls HrpN-induced drought tolerance in Arabidopsis. Planta 221:313-327

Flexas J, Ortuño MF, Ribas-Carbo M, Diaz-Espejo A, Flórez-Sarasa ID, Medrano H (2007) Mesophyll conductance to $\mathrm{CO}_{2}$ in Arabidopsis thaliana. New Phytol 175:501-511

Flexas J, Barbour MM, Brendel O, Cabrera HM, Carriquí M, DíazEspejo A, Douthe C, Dreyer E, Ferrio JP, Gago J, Gallé A, 
Galmés J, Kodama N, Medrano H, Niinemets Ü, Peguero-Pina JJ, Pou A, Ribas-Carbó M, Tomás M, Tosens T, Warren CR (2012) Mesophyll diffusion conductance to $\mathrm{CO}_{2}$ : an unappreciated central player in photosynthesis. Plant Sci 193-194:70-84

Foster KR, Miller FR, Childs KL, Morgan PW (1994) Genetic regulation of development in Sorghum bicolor. VIII. Shoot growth, tillering, flowering, gibberellin biosynthesis, and phytochrome levels are differentially affected by dosage of the $m a_{3}^{\mathrm{R}}$ allele. Plant Physiol 105:941-948

Gamble RL, Qu X, Schaller GE (2002) Mutational analysis of the ethylene receptor ETR1. Role of the histidine kinase domain in dominant ethylene insensitivity. Plant Physiol 128:1428-1438

Guzmán P, Ecker JR (1990) Exploiting the triple response of Arabidopsis to identify ethylene-related mutants. Plant Cell 2: 513-523

He SY, Huang HC, Collmer H (1993) Pseudomonas syringae pv. syringae harpin $_{\mathrm{pss}}$ : a protein that is secreted via the hrp pathway and elicits the hypersensitive response in plants. Cell 73:1255-1266

Heckwolf M, Pater D, Hanson DT, Kaldenhoff R (2011) The Arabidopsis thaliana aquaporin AtPIP1;2 is a physiologically relevant $\mathrm{CO}_{2}$ transport facilitator. Plant J 67:795-804

Ji Z, Song C, Lu X, Wang J (2011) Two coiled-coil regions of Xanthomonas oryzae pv. oryzae harpin differ in oligomerization and hypersensitive response induction. Amino Acids 40:381-392

Kaldenhoff R (2012) Mechanisms underlying $\mathrm{CO}_{2}$ diffusion in leaves. Curr Opin Plant Biol 15:276-281

Kim JF, Beer SV (2000) Hrp genes and Harpins of Erwinia amylovora: a decade of discovery. In: Vanneste JL (ed) Fire blight and its causative agent Erwinia amylovora. CAB International, Wallingford, pp 141-162

Kourill R, Ilik P, Naus J, Schoefs B (1999) On the limits of applicability of spectrophotometric and spectrofluorimetric methods for the determination of chlorophyll a/b ratio. Photosyn Res 62:107-116

Lang CA (1958) Simple micro-determination of Kjeldahl nitrogen in biological materials. Anal Chem 30:1692-1694

Lee J, Klessig DF, Nurnberger T (2001a) A harpin binding site in tobacco plasma membranes mediates activation of the pathogenesis-related gene HIN1 independent of extracellular calcium but dependent on mitogen-activated protein kinase activity. Plant Cell 13:1079-1093

Lee J, Klusener B, Tsiamis G, Stevens C, Neyt C, Tampakaki AP, Panopoulos NJ, Noller J, Weiler EW, Cornelis GR, Mansfield JW,

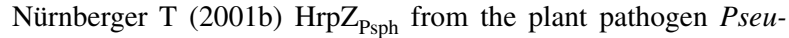
domonas syringae pv. phaseolicola binds to lipid bilayers and forms an ion-conducting pore in vitro. Proc Natl Acad Sci USA 98:289-294

Li XJ, Zhao YY, You ZZ, Dong HS, Zhang CL (2014) The Hpa1 harpin needs nitroxyl terminus to promote vegetative growth and leaf photosynthesis in Arabidopsis. J Biosci 39 (in press)

Liscum E, Reed JW (2002) Genetics of Aux/IAA and ARF action in plant growth and development. Plant Mol Biol 49:387-400

Liu YD, Zhang SQ (2004) Phosphorylation of 1-aminocyclopropane1-carboxylic acid synthase by MPK6, a stress-responsive mitogen-activated protein kinase, induces ethylene biosynthesis in Arabidopsis. Plant Cell 16:3386-3399

Liu F, Liu H, Jia Q, Wu X, Guo X, Zhang S, Song F, Dong H (2006) The internal glycine-rich motif and cysteine suppress several effects of the $\mathrm{HpaG}_{\mathrm{Xooc}}$ protein in plants. Phytopathology 96:1052-1059

Liu RX, Chen L, Jia ZH, Lü BB, Shi HJ, Shao W, Dong HS (2011) Transcription factor AtMYB44 regulates induced expression of the ETHYLENE INSENSITIVE2 gene in Arabidopsis responding to a harpin protein. Mol Plant-Microbe Interact 24:377-389

Lü BB, Li XJ, Sun WW, Li L, Gao R, Zhu Q, Tian SM, Fu MQ, Yu HL, Tang XM, Zhang CL, Dong HS (2013a) AtMYB44 regulates resistance to the green peach aphid and diamondback moth by activating EIN2-affected defences in Arabidopsis. Plant Biol (Stuttg) 15:841-850

Lü P, Kang M, Jiang X, Dai F, Gao J, Zhang C (2013b) RhEXPA4, a rose expansin gene, modulates leaf growth and confers drought and salt tolerance to Arabidopsis. Planta 237:1547-1559

Miao WG, Wang XB, Li M, Song CF, Wang Y, Hu DW, Wang JS (2010) Genetic transformation of cotton with a harpin-encoding gene $h p a_{X o o}$ confers an enhanced defense response against different pathogens through a priming mechanism. BMC Plant Biol 10:67

Nanda AK, Andrio E, Marino D, Pauly N, Dunand C (2010) Reactive oxygen species during plant-microorganism early interactions. J Integr Plant Biol 52:195-204

Oh CS, Beer SV (2007) AtHIPM, an ortholog of the apple HrpNinteracting protein, is a negative regulator of plant growth and mediates the growth-enhancing effector of $\mathrm{HrpN}$ in Arabidopsis. Plant Physiol 145:426-436

Olmedo G, Guo HW, Gregory BD, Nourizadeh SD, Aguilar- Henonin L, Li HJ, An FY, Guzman P, Ecker JR (2006) Ethylene-insensitive 5 encodes a $5^{\prime} \rightarrow 3^{\prime}$ exoribonuclease required for regulation of the EIN3-targeting F-box proteins EBF1/2. Proc Natl Acad Sci USA 103:13286-13293

Peng JL, Bao ZL, Ren HY, Wang JS, Dong HS (2004) Expression of harpin $_{\mathrm{Xoo}}$ in transgenic tobacco induces pathogen defense in the absence of hypersensitive cell death. Phytopathology 94:1048-1055

Penninckx IA, Thomma BP, Buchala A, Metraux JP, Broekaert WF (1998) Concomitant activation of jasmonate and ethylene response pathways is required for induction of a plant defensin gene in Arabidopsis. Plant Cell 10:2103-2113

Pieterse CM, van Wees SC, van Pelt JA, Knoester M, Laan R, Gerrits H, Weisbeek PJ, van Loon LC (1998) A novel signaling pathway controlling induced systemic resistance in Arabidopsis. Plant Cell 10:1571-1580

Potuschak T, Vansiri A, Binder BM, Lechner E, Vierstra RD, Genschik P (2006) The exoribonuclease XRN4 is a component of the ethylene response pathway in Arabidopsis. Plant Cell 18:3047-3057

Ren HY, Gu GY, Long JY, Wu TQ, Song T, Zhang SJ, Chen ZY, Dong HS (2006a) Combinative effects of a bacterial type-III effector and a biocontrol bacterium on rice growth and disease resistance. J Biosci 31:617-627

Ren HY, Song T, Wu TQ, Sun L, Liu YX, Yang FF, Chen ZY, Dong HS (2006b) Effects of a biocontrol bacterium on growth and defence of transgenic rice plants expressing a bacterial type-III effector. Annals Microbiol 56:281-287

Ren XY, Liu F, Bao ZL, Zhang CL, Wu X, Chen L, Liu RX, Dong HS (2008) Root growth of Arabidopsis thaliana is regulated by ethylene and abscisic acid signaling interaction in response to $\mathrm{HrpN}_{\mathrm{Ea}}$, a bacterial protein of harpin group. Plant Mol Biol Rep 26:225-240

Rose JKC, Bennett AB (1999) Cooperative disassembly of the cellulose-xyloglucan network of plant cell walls: parallels between cell expansion and fruit ripening. Trends Plant Sci 4:176-183

Sampedro J, Cosgrove DJ (2005) The expansin superfamily. Genome Biol 6:242

Sang S, Li X, Gao R, You Z, Lü B, Liu P, Ma Q, Dong H (2012) Apoplastic and cytoplasmic location of harpin protein $\mathrm{Hpa}_{\mathrm{Xoo}}$ plays different roles in $\mathrm{H}_{2} \mathrm{O}_{2}$ generation and pathogen resistance in Arabidopsis. Plant Mol Biol 79:375-391

Schaller GE, Bleecker AB (1995) Ethylene-binding sites generated in yeast expressing the Arabidopsis ETR1 gene. Science 270:1809-1811

Shi LW (2012) SPSS19.0 Statistical analysis from accidence to conversance (in Chinese). Tsinghua University Press, Beijing, pp 109-143 
Sloan J, Backhaus A, Malinowski R, McQueen-Mason S, Fleming AJ (2009) Phased control of expansin activity during leaf development identifies a sensitivity window for expansin-mediated induction of leaf growth. Plant Physiol 151:1844-1854

Soltys D, Rudzińska-Langwald A, Gniazdowska A, Wiśniewska A, Bogatek R (2012) Inhibition of tomato (Solanum lycopersicum L.) root growth by cyanamide is due to altered cell division, phytohormone balance and expansin gene expression. Planta 236:1629-1638

Sponsel VM, Schmidt FW, Porter SG, Nakayama M, Kohlstruk S, Estelle M (1997) Characterization of new gibberellin-responsive semidwarf mutants of Arabidopsis. Plant Physiol 115:1009-1020

Strobel RN, Gopalan JS, Kuc JA, He SY (1996) Induction of systemic acquired resistance in cucumber by Pseudomonas syringae pv. syringae $61 \mathrm{HrpZ}_{\mathrm{Pss}}$ protein. Plant J 9:431-439

Torres MA (2010) ROS in biotic interactions. Plant Physiol 138:414-429

Uehlein N, Sperling H, Heckwolf M, Kaldenhoff R (2012) The Arabidopsis aquaporin PIP1;2 rules cellular $\mathrm{CO}_{2}$ uptake. Plant Cell Environ 35:1077-1083

Vivian-Smith A, Koltunow AM (1999) Genetic analysis of growthregulator-induced parthenocarpy in Arabidopsis. Plant Physiol 121:437-451

Vogler H, Caderas D, Mandel T, Kuhlemeier C (2003) Domains of expansin gene expression define growth regions in the shoot apex of tomato. Plant Mol Biol 53:267-272

Wang KL, Li H, Ecker JR (2002) Ethylene biosynthesis and signaling networks. Plant Cell 14:S131-S151

Wang X, Li M, Zhang J, Zhang Y, Zhang G, Wang J (2007) Identification of a key functional region in harpins from Xanthomonas that suppresses protein aggregation and mediates harpin expression in E. coli. Mol Biol Rep 34:189-198

Wang X, Song C, Miao W, Ji Z, Wang B, Zhang Y, Zhang J, Hu JS, Borth W, Wang J (2008) Mutations in the N-terminal coding region of the harpin protein Hpal from Xanthomonas oryzae cause loss of hypersensitive reaction induction in tobacco. Appl Microbiol Biotechnol 81:359-369

Wang G, Gao Y, Wang J, Yang L, Song R, Li X, Shi J (2011) Overexpression of two cambium-abundant Chinese fir (Cunninghamia lanceolata) $\alpha$-expansin genes ClEXPA1 and ClEXPA2 affect growth and development in transgenic tobacco and increase the amount of cellulose in stem cell walls. Plant Biotechnol J 9:486-502

Wei ZM, Laby RJ, Zumoff CH, Bauer DW, He SY, Collmer A, Beer SV (1992) Harpin, elicitor of the hypersensitive response produced by the plant pathogen Erwinia amylovora. Science 257:85-88

Wu XJ, Wu TQ, Long JY, Yin Q, Zhang Y, Chen L, Liang Y, Liu RX, Gao TC, Dong HS (2007) Productivity and biochemical properties of green tea in response to a bacterial type-III effector protein and its variants. J Biosci 32:1119-1132

Xu YL, Li L, Wu K, Peeters AJ, Gage DA, Zeevaart JA (1995) The GA5 locus of Arabidopsis thaliana encodes a multifunctional gibberellin 20-oxidase: molecular cloning and functional expression. Proc Natl Acad Sci USA 92:6640-6644

Yang QH, Lu W, Hu ML, Wang CM, Zhang RX, Yao M, Wan JM (2003) QTL and epistatic interaction underlying leaf chlorophyll and $\mathrm{H}_{2} \mathrm{O}_{2}$ content variation in rice (Oryza sativa $\mathrm{L}$.). Yi Chuan Xue Bao 30:245-250

Zhang CL, Bao ZL, Liang Y, Yang X, Wu X, Hong X, Dong HS (2007) Abscisic acid mediates Arabidopsis drought tolerance induced by $\mathrm{HrpN}_{\mathrm{Ea}}$ in the absence of ethylene signaling. Plant Mol Biol Rep 25:94-114

Zhang CL, Shi HJ, Chen L, Wang XM, Lü BB, Zhang SP, Liang YA, Liu RX, Qian J, Sun WW, You ZZ, Dong HS (2011a) Harpininduced expression and transgenic overexpression of the phloem protein gene AtPP2-A1 in Arabidopsis repress phloem feeding of the green peach aphid Myzus persicae. BMC Plant Biol 11:11

Zhang L, Xiao S, Li W, Feng W, Li J, Wu Z, Gao X, Liu F, Shao M (2011b) Overexpression of a Harpin-encoding gene $h r f l$ in rice enhances drought tolerance. J Exp Bot 62:4229-4238

Zhao MR, Han YY, Feng YN, Li F, Wang W (2012) Expansins are involved in cell growth mediated by abscisic acid and indole3 -acetic acid under drought stress in wheat. Plant Cell Rep 31:671-685

Zhu WG, Magbanua MM, White FF (2000) Identification of two novel $h p a G$-associated genes in the $h p a G$ gene cluster of Xanthomonas oryzae pv. oryzae. J Bacteriol 182:1844-1853 